\title{
Smart Bilayer Polymer Reactor with Cascade/Non-cascade Switching Catalyst Characteristics
}

\author{
Wenjing Wei ${ }^{1,2}$, Panpan Xiao ${ }^{2}$, Vijay Kumar Thakur ${ }^{1,2 *}$, Songjun Li ${ }^{2 *}$ \\ ${ }^{1}$ Enhanced Composites and Structures Center, School of Aerospace, Transport and Manufacturing, Cranfield \\ University, Bedfordshire MK43 OAL, UK \\ ${ }^{2}$ Research School of Polymeric Materials, School of Materials Science \& Engineering, Jiangsu University, Zhenjiang, \\ China
}

\begin{abstract}
This study is aimed at addressing how to furnish the catalysts with cascade/non-cascade switching catalytic ability. Inspired from the "soft" properties and divisional isolation function in natural biological systems, this objective was accomplished by developing a new class of hydrogel made of two unique functional layers with different temperature responses where each may self-govern coupled process at a specific temperature condition. This hydrogel polymer catalyst showed almost no catalytic activity at relatively low temperatures $\left(<37^{\circ} \mathrm{C}\right)$ as both channels of bilayer hydrogel polymer catalyst were closed. At modest temperatures (between $37^{\circ} \mathrm{C}$ and $50^{\circ} \mathrm{C}$ ), the first step of the tandem reaction (the hydrolysis of p-nitrophenyl acetate (NPA)) showed significant reactivity that arises from the relaxing of the weak polymer complexes hydrogel layer. This allowed NPA to gain entrance to the acidic catalytic active center of the hydrogel. At relatively high temperatures $\left(>50^{\circ} \mathrm{C}\right)$, this hydrogel polymer catalyst further showed significant reactivity towards the hydrolysis reaction of NPA and reduction reaction of intermediate product p-nitrophenol (NP). It mainly results from the opening of both weak polymer complexes hydrogel layer and stronger polymer complexes hydrogel layer, allowing entrance to both acidic catalytic active center and metal nanoparticles active center. In this way, this hydrogel polymer catalyst demonstrated a controllable cascade/ non-cascade catalytic ability. This suggested protocol provides the inspiration with struggling tandem catalysts, which allows opportunities to finely switchable tandem processes.
\end{abstract}

Keywords: Hydrogel catalyst; bilayer polymer; tandem catalysis; self-controlled catalysis

\footnotetext{
* Email address: Vijay.Kumar@cranfield.ac.uk (V.K. Thakur)

* Email address: 1sjchem@ujs.edu.cn (S. Li)
} 


\section{Introduction}

Tandem reactions, which involve the sequential chemical reactions to proceed in a concurrent style, have attracted lots of researchers' attention owing to their high atom economy, step-saving and biomimetic nature to name a few [1-3]. Further selfmodulation of the tandem reactions would enable the complicated reactions into a more controllable and programmable way and thus achieving one-pot catalytic processes [4, 5]. To hit this point, a lot of recent researches are being focused on studying about the control of configurations-activity relationship at the novel catalysts like functional microspheres and hierarchical structure, making possible either regulated channel for substrate or micro phase separation from the catalytic systems [6-10]. In this way, the self-controlled tandem catalysts are able to achieve the self-modulated sequential reactions [11-15]. Despite the progress [16, 17], there are not too many practical applications of the self-controlled tandem catalysts in recent days. One significant problem comes from the complicated process of the practical tandem processes, which contains a series of different catalytic processes, sometimes incorporating both cascade and non-cascade processes. At present, it is difficult to prepare such self-controlled catalysts by simply combining and copying the switchable catalysts in simple reactions. Therefore, the development of a novel catalyst to realize efficient switchable control is a great challenge in complicated tandem catalysis and is need of the hour.

For centuries, scientists have learned to resolve complicated problems based on inspiration sought from nature $[18,19]$. Nature is able to shuttle reactants and products through individual compartments allowing for cascade or tandem reaction pathways combining (incompatible) transformations for complex molecule synthesis [20]. Sometimes it is essential for biological systems' survival to achieve self-controlled ability in the multi-pathway reaction processes (typically catalytic hydrolysis and redox reactions) [21, 22]. The answer behind this lies in the "soft" morphology and "arbitrary" piling-up structures, showing a fine modulation of the substrate channels to the internal active species, enabling self-control from simple reactions to complicated tandem processes [23, 24]. Owing to their reversible switching properties in response to different external stimuli [25-27], these systems are capable of improving the mass transports of reactants/products in aqueous solution, switching the sequential catalytic process on and off [28-30]. As a result, natural biological systems show us perfect 
examples on how to cater to complicated reactions by finely self-controlled ability [3134].

Enlightened by this principle, herein, a bilayer polymer reactor that was capable of controlling cascade reaction processes by its own deformations upon changing temperature was prepared. One of the layers in this hydrogel was made by weak polymer complexes between Poly (2-acrylamide)-2-methylpropanesulfonic acid (PAMPS) and polyacrylamide (PAM). This layer can conduct the hydrolysis of NPA by controlling the opening or not of the channel according to external temperature. When the temperature is higher than $37^{\circ} \mathrm{C}$, the electrostatic force between the copolymers is destroyed and the reaction channel is open, resulting in the hydrolysis of NPA. The other layer was fabricated with stronger polymer complexes poly (1-vinyl imidazole) (PVI) and poly (2-trifluoromethylacrylic acid) (PTFMA) with silver nanoparticles encapsulated, which can control the exposure of silver nanoparticles for reactions of intermediate. When the temperature is above $53^{\circ} \mathrm{C}$, the silver nanoparticles are exposed as the channel opens, resulting in the reduction of intermediate NP. In this way, the novel polymer catalyst was furnished with hierarchical access capable of modulating tandem catalytic ability. This double temperature-responsive polymer reactor (named "DTR") with responsive abilities to two different temperatures, was constructed from two different interactions. One of them is a relatively stronger polymer complex [35] (between PVI and PTFMA) with Ag nanoparticles encapsulated, and another is a weak hydrogen bond (between PAMPS and PAM) [36]. The selfassembly hierarchical pathways of different polymer hydrogel layer molecules act as molecular switches to provide ordered access to different catalytic active centres. As proposed in Scheme 1, at relatively low temperatures, the closed access in this polymer catalyst would block substrate from the catalytic active centres, resulting in poor catalytic reactivity (Status A). The access for NPA, however, allowed with increasing temperature, arising from the dissociation of the PAMPS-PAM complexes interactions (Status B). At relatively high temperatures, NP can be reduced to AP by encapsulated metal nanoparticles, resulting from the dissociation of the PVI-PTFMA complexes (Status C). In this way, the hierarchical access allows for the occurrence of the catalysts with self-controlled cascade catalytic-ability. The objective of this study is to demonstrate that polymer catalysts with self-controlled catalytic ability can be prepared by this novel protocol, opening up new opportunities to develop smart catalysts for controlled cascade chemical processes. 


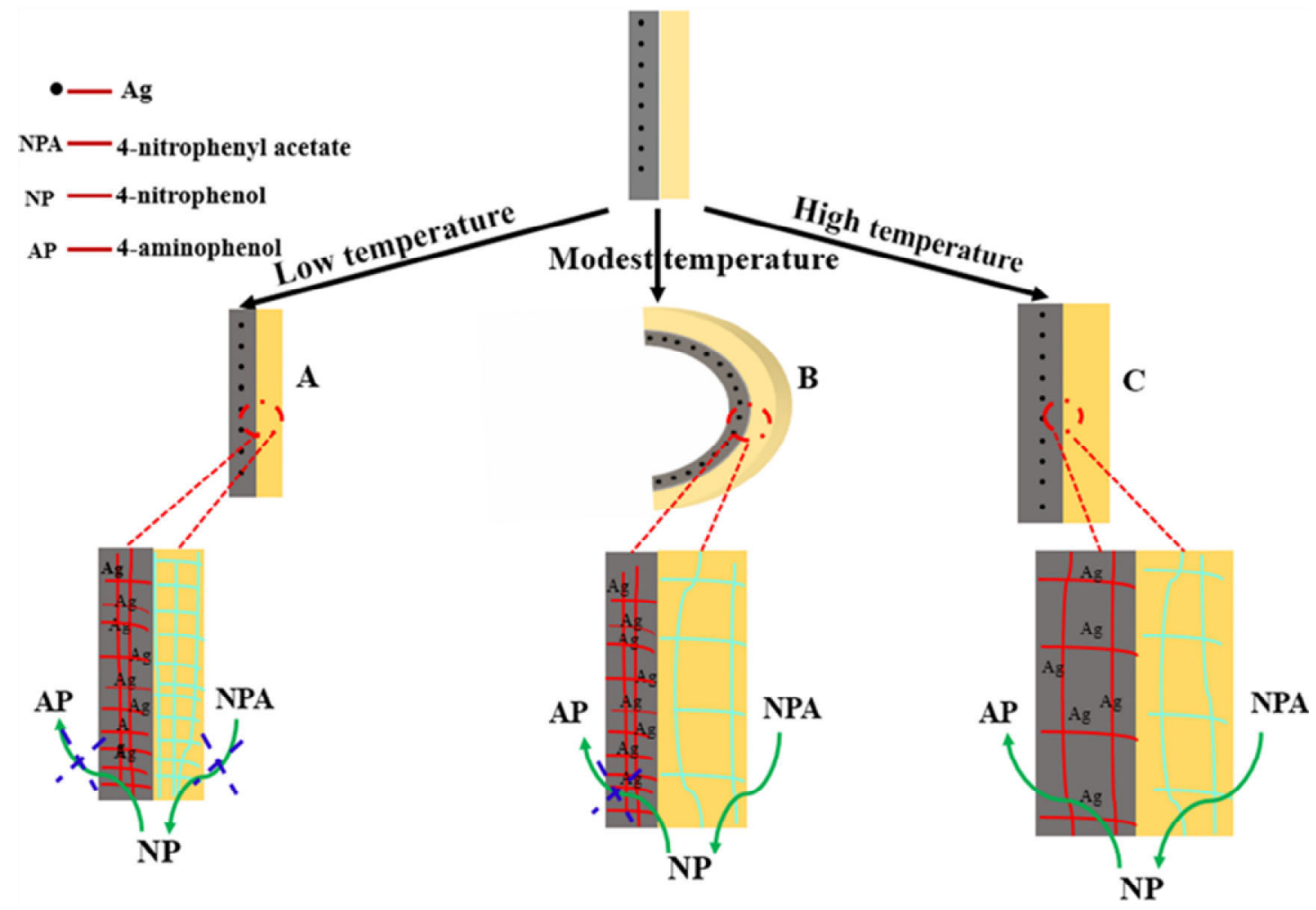

Scheme 1. Proposed mechanism for the novel polymer catalyst

\section{Experiment}

\subsection{Preparation of polymer catalysts}

Unless otherwise noted, the chemicals used were of analytic grade and used as received from Sigma-Aldrich. The novel polymer catalyst, as discussed, was prepared in the form of a bilayer of switchable layer hydrogels layer with different response temperatures (cf. Scheme 1). To connect both layers, the switchable layer with a higher temperature response was first prepared by polymerization and then exposed by one side of the layer to a solution with a relatively low temperature response, intended for preparing the coupled second layer, which allowed the formation of an interpenetrating network structure between the two layers. In this way, both layers were connected (as Scheme 2 showed). Firstly, the functional monomers 2-acrylamido-2methylpropanesulfonic acid (AMPS) and acrylamide (AAM), 2-trifluoromethylacrylic acid (TFMA) and 1-vinyl imidazole (VI) were used in a stoichiometric molar ratio to ensure the entire complexation between amino groups and sulfonic groups, hydroxyl and imidazole moieties, which would be further discussed afterward in 3.1. In detail, 
stoichiometric VI/TFMA complexes (VI: 0.285g; 3.0mmol) (TFMA: 0.372g; $2.61 \mathrm{mmol})$ were dissolved in dimethylsulfoxide $(10.0 \mathrm{~mL})$. After being dispersed and deoxygenated with sonication and nitrogen, the initiator AIBN (0.092 g) and crosslinker $\mathrm{N}, \mathrm{N}$ '-methylene bisacrylamide (MBA) (0.177 g; 1.15mmol), along with $\mathrm{AgNO}_{3}(0.51$ g; 3mmol) were added. The solution was rapidly injected into a glass cell for polymerization. The mixture system was conducted at $70^{\circ} \mathrm{C}$ for $1 \mathrm{~h}$ to produce the VI/TFMA hydrogel and encapsulated ionic Ag was then reduced by an excess of sodium borohydride (tenfold, with regard to ionic Ag). It is then immersed in deionized water for a period of time to remove unreacted monomer.

The second layer of the PAMPS/AM hydrogel was synthesized on the first layer in a way similar to that previously mentioned. In detail, AM $(0.4 \mathrm{~g} ; 5.63 \mathrm{mmol})$, AMPS $(0.941 \mathrm{~g} ; 4.54 \mathrm{mmol})$ and $\mathrm{MBA}(0.0375 \mathrm{~g} ; 0.24 \mathrm{mmol})$ was dissolved in deionized water $(4 \mathrm{ml})$; potassium persulfate $(0.0532 \mathrm{~g})$ and potassium bisulfite $(0.0247 \mathrm{~g})$ was dissolved in deionized water $(2 \mathrm{ml})$. Then the two solutions were mixed and poured into the glass cell. The curing of the second layer was conducted at $25^{\circ} \mathrm{C}$ for $10 \mathrm{~min}$, accompanying with the reactive solution penetrated into the surface of the first layer to create a strong interpenetrating network structure between the two layers. After complete polymerization, the bilayer hydrogel (DTR) was prepared. In this way, the novel catalyst was synthesized.

For a contrastive study, two controls named "LTR", "HTR" respectively were also prepared under comparable conditions. "LTR" was a hydrogel polymer catalytic reactor with relatively low-temperature responsive ability (with the only acidic site), in which the hydrogel was made entirely of (AMPS and AM). "HTR" was the switchable Ag catalyst made of TFMA, VI and $\mathrm{AgNO}_{3}$, with high response temperature (catalytic of metal nanoparticles, only). In this way, these controls, along with DTR were prepared. The objective of this study was to demonstrate that the self-controlled tandem catalyticability can be realized by this bilayer smart polymer reactor with different temperatureresponsive ability, which may provide new inspirations for controlled tandem catalytic reactors. 


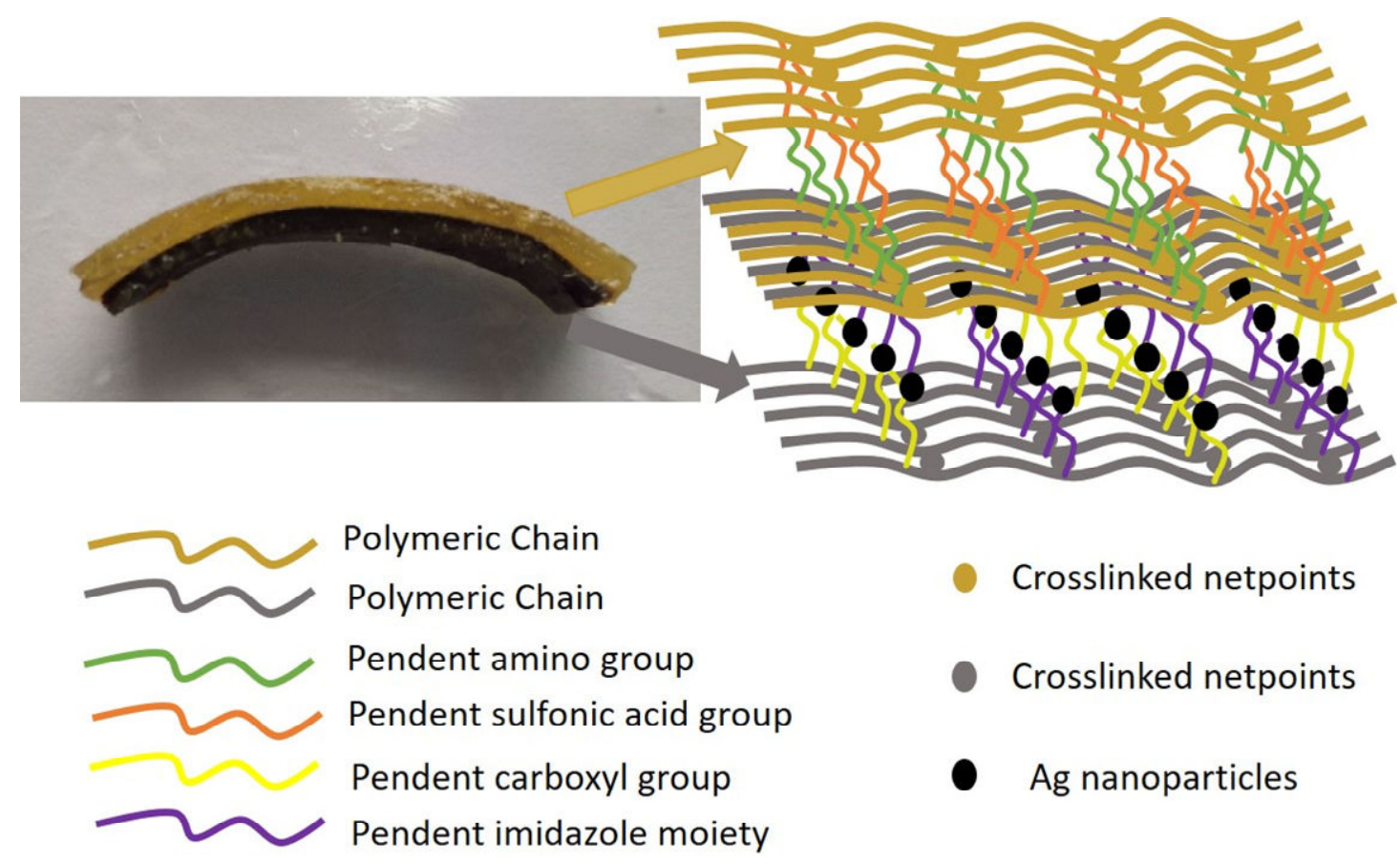

Scheme 2. Bilayer structural scheme of the polymer reactor

\subsection{Characterization}

The TEM images of the prepared catalysts were obtained using a JEM-2100 transmission electron microscope (TEM) (Japan). The surface morphology was observed using a JSM-7800F scanning electron microscope (SEM) (Japan). The FTIR spectra were obtained using a Nicolet MX-1E apparatus (USA). The absorption bands of the surface plasma resonance (SPR) were obtained using a Lambda $25 \mathrm{UV}$ spectrophotometer (USA). The energy-dispersive spectra (EDS) were obtained using a MIRA3-XMU apparatus (USA). X-ray diffraction (XRD) data were measured on the X'Pert PRO MPD powder X-ray diffractometer. The change of shape upon temperature was recorded with a digital camera in which the slice of the prepared catalysts was immersed in water.

\subsection{Self-switchable interactions}

The self-switchable interactions between PAM and PAMPS as well as between PVI and PTFMA were studied as a function of temperature using dynamic light scattering (DLS) (NanoZS-ZEN3600, UK). For equilibrium, all the concerned samples were kept at the specified temperatures for at least $10 \mathrm{~min}$ before acquiring hydrodynamic radii $(\mathrm{Rh})$. For a comparison between the smart reactors DTR, we have also conducted DLS tests on HTR, LTR. 


\subsection{Catalysis test}

The catalytic properties of the prepared polymer reactors were evaluated in the batch format in PBS buffer solution ( $\mathrm{pH}=7$; containing 10vol\% methanol). The initial concentration of NPA was $0.02 \mu \mathrm{mol} \mathrm{mL} \mathrm{m}^{-1}(10 \mathrm{~mL} \mathrm{PBS}, \mathrm{pH} 7.0)\left(\mathrm{NaBH}_{4}\right.$ : if present, tenfold in contrast to NPA). The solid content of the polymer reactors was $0.1 \mathrm{mg} \mathrm{mL}^{-}$

${ }^{1}$ in each test. The catalytic behavior was spectrophotometrically monitored and the catalytic activities were determined from the average of triple runs. Given the potential effect of spontaneous reactions on the catalytic process, the reactions of NPA in the absence of catalysts were also run under the comparable conditions and accordingly the effects had been deducted from the reported overall activities of these catalysts.

\subsection{Electrochemical tests}

Electrochemical tests were further performed to investigate the catalytic mechanism between the prepared polymer catalysts and substrate [12]. Using an electrochemical workstation furnished with a three-electrode configuration (Au-plate working electrode, Pt-wire counter electrode and $\mathrm{Ag} / \mathrm{AgCl}$ reference electrode) (CHI760E, China), polymer catalysts $(20.0 \mathrm{mg})$ that pre-absorbed ca. $4 \mu \mathrm{mol}$ substrate (i.e., NP) were placed into a cuvette encircled by a diffusion-eliminating sonication apparatus (supporting electrolyte: PBS buffer solution; $15 \mathrm{~mL}, \mathrm{KCl} 0.1 \mathrm{~g}$ ). The substrate desorbed transiently was cyclic-voltammetrically scanned by using the workstation until a stable desorption/reduction profile was achieved (scanning range, -0.45 to $0.1 \mathrm{~V}$; rate, $0.05 \mathrm{~V} / \mathrm{s})$.

\section{Results and discussion}

\subsection{Optimized interactions within the prepared catalysts}

As explained, the switchable ability at the DTR catalyst mainly results from the complementary interactions between the two different temperature-responsive layers. The association/dissociation process at different layers endows self-controlled access to the acidic/reductive active centers. It is known that excess of either monomer would lead to the steric mismatch between PTFMA and PVI as well as between PAM and PAMPS moieties. It results in unsaturated interactions and defective responsiveness. 
Only the stoichiometric PVI-PTFMA and PAM-PAMPS interactions would exhibit complete association/dissociation, therefore showing the best switching responsiveness [37]. Given that the complementary interactions between different functional groups can induce an alterable electronic-transition at electronic clouds (valent electrons) and accordingly a change in the electronic transition, the specific study about the interactions could be studied with UV titration [35]. By using titration, Fig 1 and 2 exhibited the UV spectra shifting as a function of the TFMA/VI and AMPS/ AM. As shown in Fig. 1, the titration of TFMA to VI led to a shift in the UV spectra (marked with broken lines). The shift achieved a maximal value when the titrated TFMA reached a critical amount (corresponding to the TFMA/VI ratio $1 \mathrm{~mol} / 1.12 \mathrm{~mol}$ ). Beyond this specific amount, there was no more shift except for increasing absorbance. This result indicated that the TFMA-VI interaction was saturated by the stoichiometric titration and reached the optimization state [35]. The outcome was similar in titrating AMPS to AM, as shown in Fig. 2. The maximal value was achieved when the AMPS / AM ratio reached $1 \mathrm{~mol} / 1.24 \mathrm{~mol}$. As such, $2.6 \mathrm{mmol}$ of TFMA $(0.3722 \mathrm{~g})$ and $3.0 \mathrm{mmol}$ of VI $(0.28 \mathrm{~g}) ; 4.54 \mathrm{mmol}$ of AMPS $(0.941 \mathrm{~g})$ and $5.63 \mathrm{mmol}$ of AM $(0.4 \mathrm{~g})$ were adopted to prepare DTR.

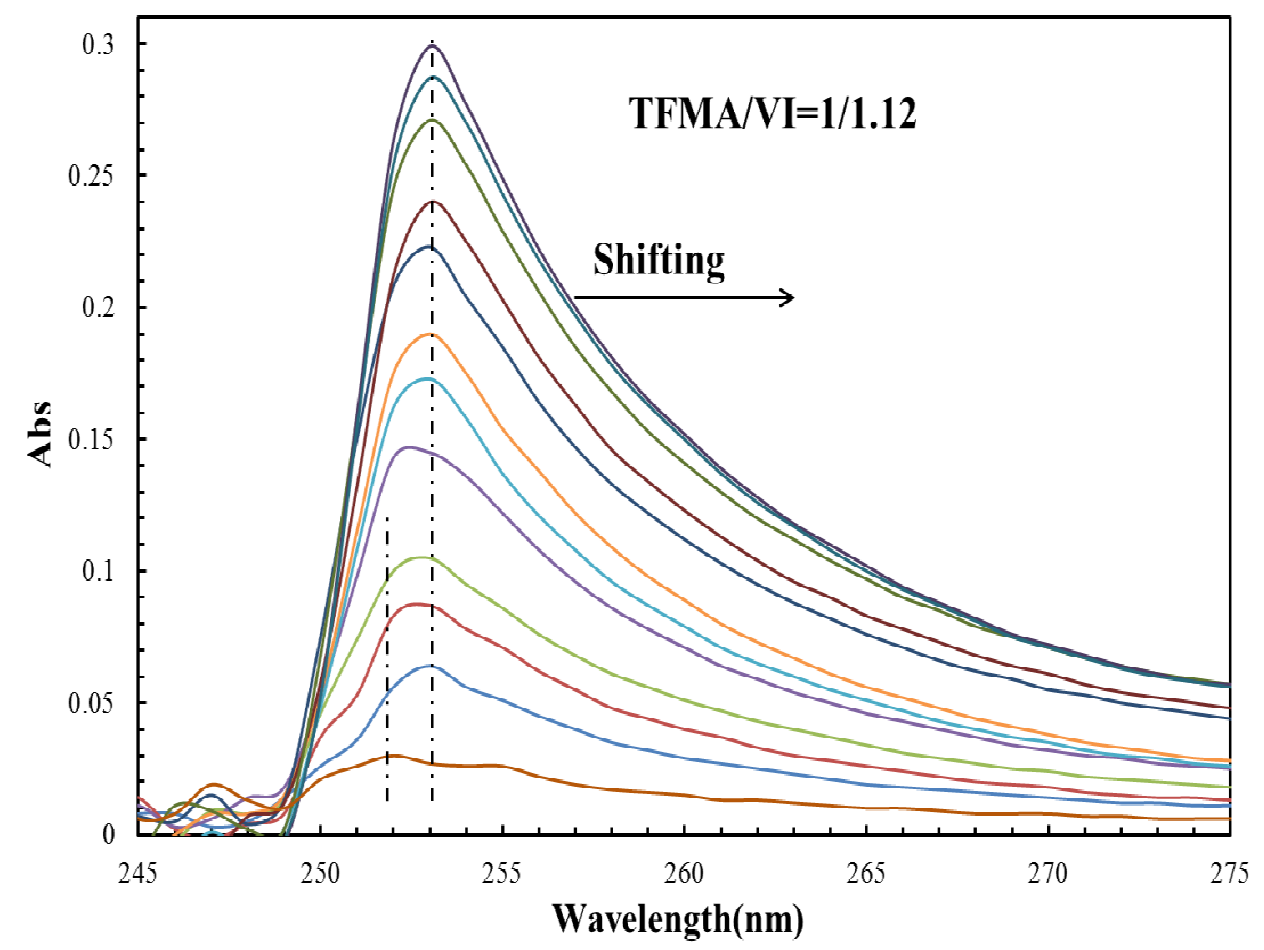

Fig 1. UV spectra shifting as a function of the TFMA/VI ratio by using UV titrations (in which, TFMA $\left(2.5 \mu \mathrm{mol} \mathrm{mL}{ }^{-1} ; 0.32 \mathrm{~mL} ; 20 \mu \mathrm{L}\right.$ per titration) was titrated into VI $\left(0.3 \mu \mathrm{mol} \mathrm{mL} \mathrm{mL}^{-1} ; 3 \mathrm{~mL}\right)$. 


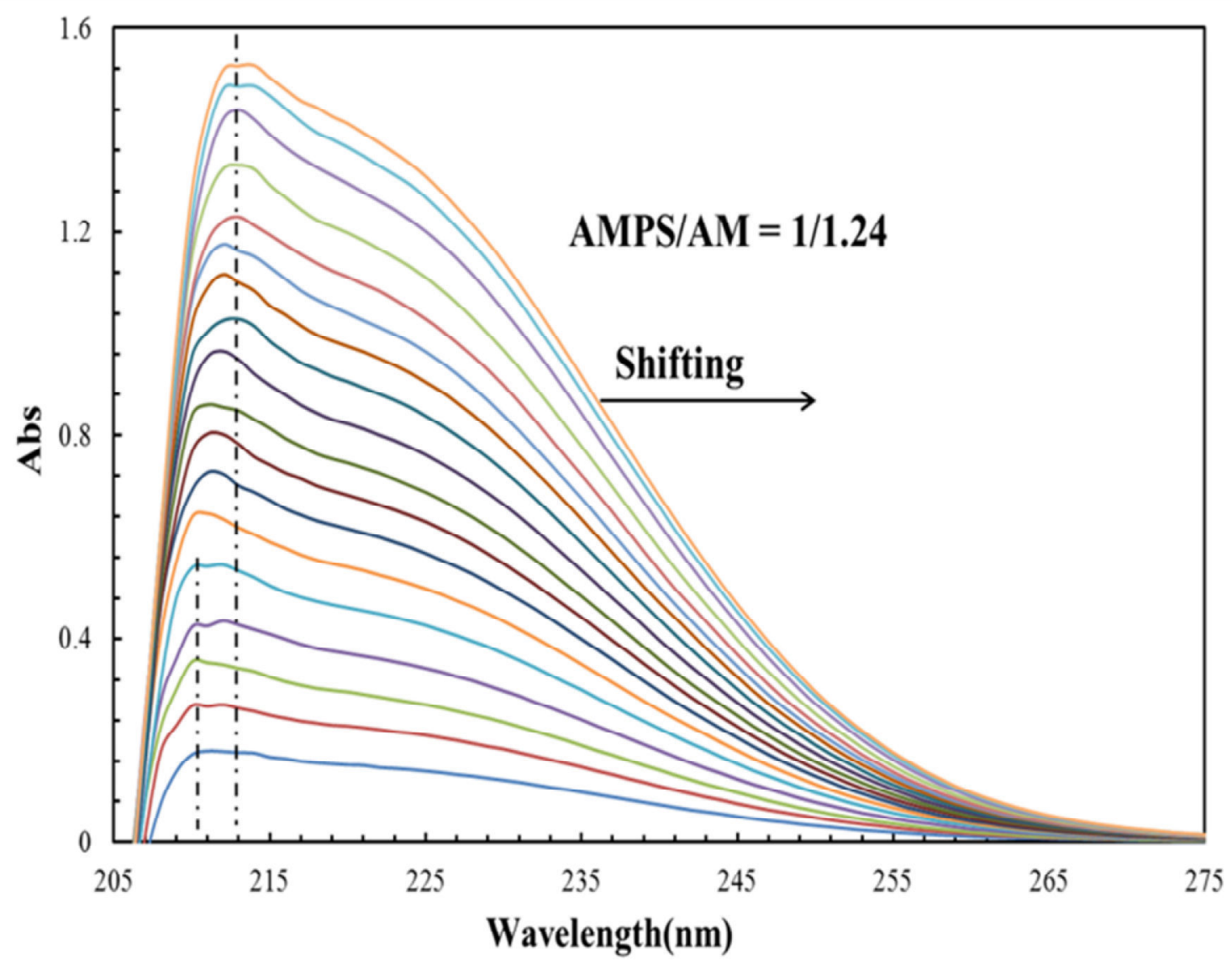

Fig 2. UV spectra shifting as a function of the AMPS/AM ratio by using UV titrations (in which, AM $\left(2 \mu \mathrm{mol} \mathrm{mL} \mathrm{m}^{-1} ; 0.3 \mathrm{~mL} ; 10 \mu \mathrm{L}\right.$ per titration) was titrated into AMPS $\left(0.25 \mu \mathrm{mol} \mathrm{mL} L^{-1} ; 3 \mathrm{~mL}\right)$.

\subsection{Analysis of composition and structure}

The prepared bilayer hydrogels have been observed by scanning electron microscope (SEM) to investigate the surface morphologies and the boundary between the first and second layers, as shown in Fig 3. It has been observed that the surface of the PTFMAPVI-Ag layer is slightly rougher than that of PAM-PAMPS because of the existence of Ag. The boundary of two layers has been found to be distinct but with tight conjunction. Even the components in two layers are different from each other. The chain entanglement and hydrogen bond existing among two different layers have been able to connect each other as well as increase the adhesion at the interface. 

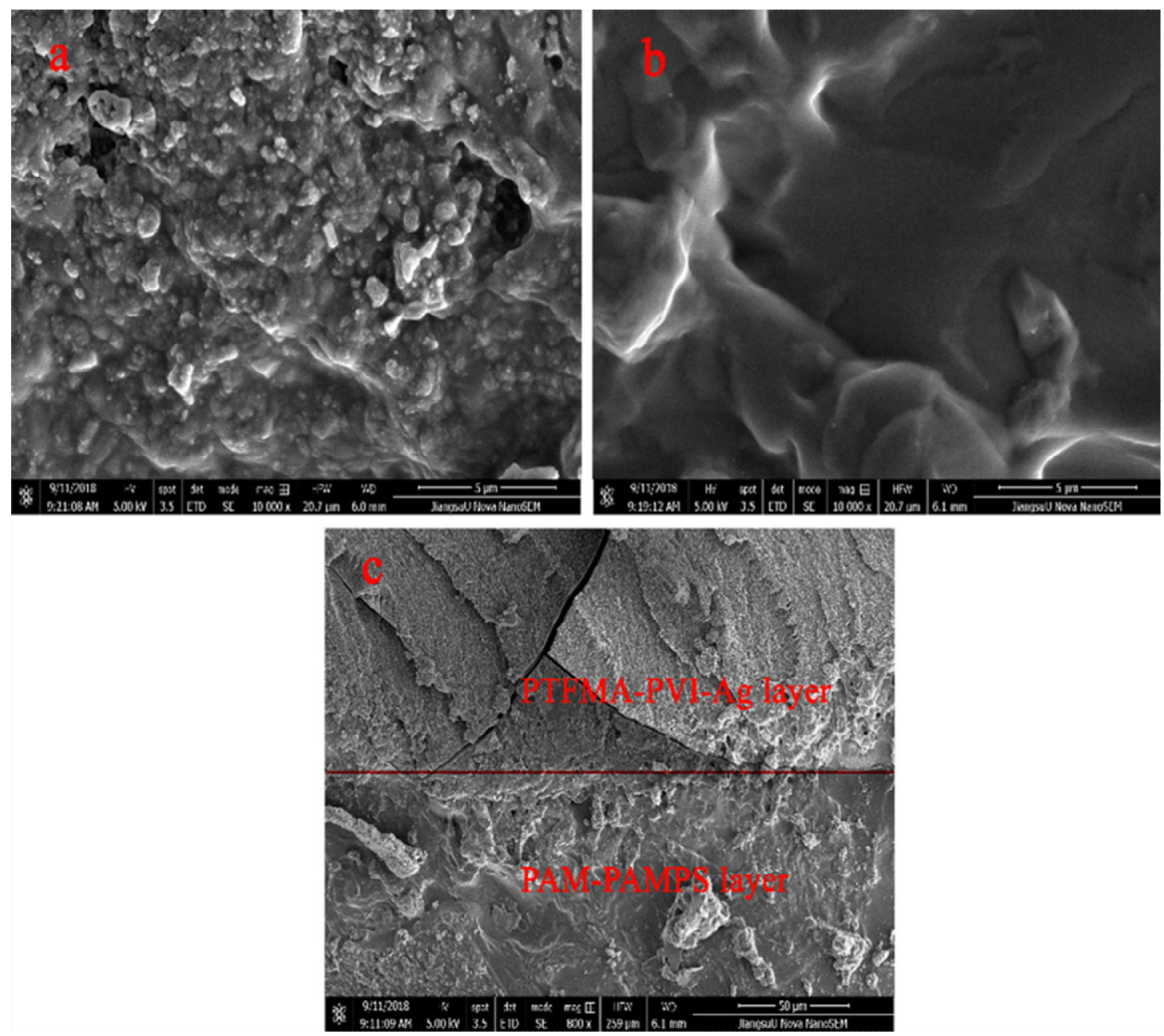

Fig 3. SEM images of two individual layers: PTFMA-PVI-Ag/ HTR (a) and PAMPAMPS/LTR (b), and the cross-section of the bilayer hydrogel /DTR(c)

FT-IR was first used to study the polymeric composition in the prepared DTR, as shown in Fig 4. Three major bands (i.e., 3000-3750, 1750 and 1000-1500 $\mathrm{cm}^{-1}$ ) appeared in the spectrum of the reactor, which is connected with the vibrating zones of $\mathrm{O}-\mathrm{H}(\mathrm{N}-\mathrm{H})$, $\mathrm{C}=\mathrm{O}$ and $\mathrm{C}-\mathrm{N}$ (C-C), respectively [21]. As the components PTFMA, PVI, AM and AMPS separately contain these vibrational groups, it is therefore difficult to clarify one specific constituent from DTR. As a result, we have also compared the FT-IR spectra of two other controls (i.e., HTR: made of PVI-PTFMA and LTR: made of PAM-PAMPS) (Fig. 4). As is shown, the DTR contains the major absorption bands of HTR and LTR controls. The spectrum of the major bands of other controls indicates the multicomponent copolymer compounded by PTFMA, PVI, PAM and PAMPS in DTR. Therefore, it has been clarified that the prepared DTR was prepared to contain the components as expected. Fig 5 shows the TEM images of polymer catalyst. Silver 
nanoparticles with a size of ca.8nm were encapsulated in the polymer reactor DTR and HTR while there were no metal nanoparticles in LTR. Hence, these polymers were prepared in the desired form.

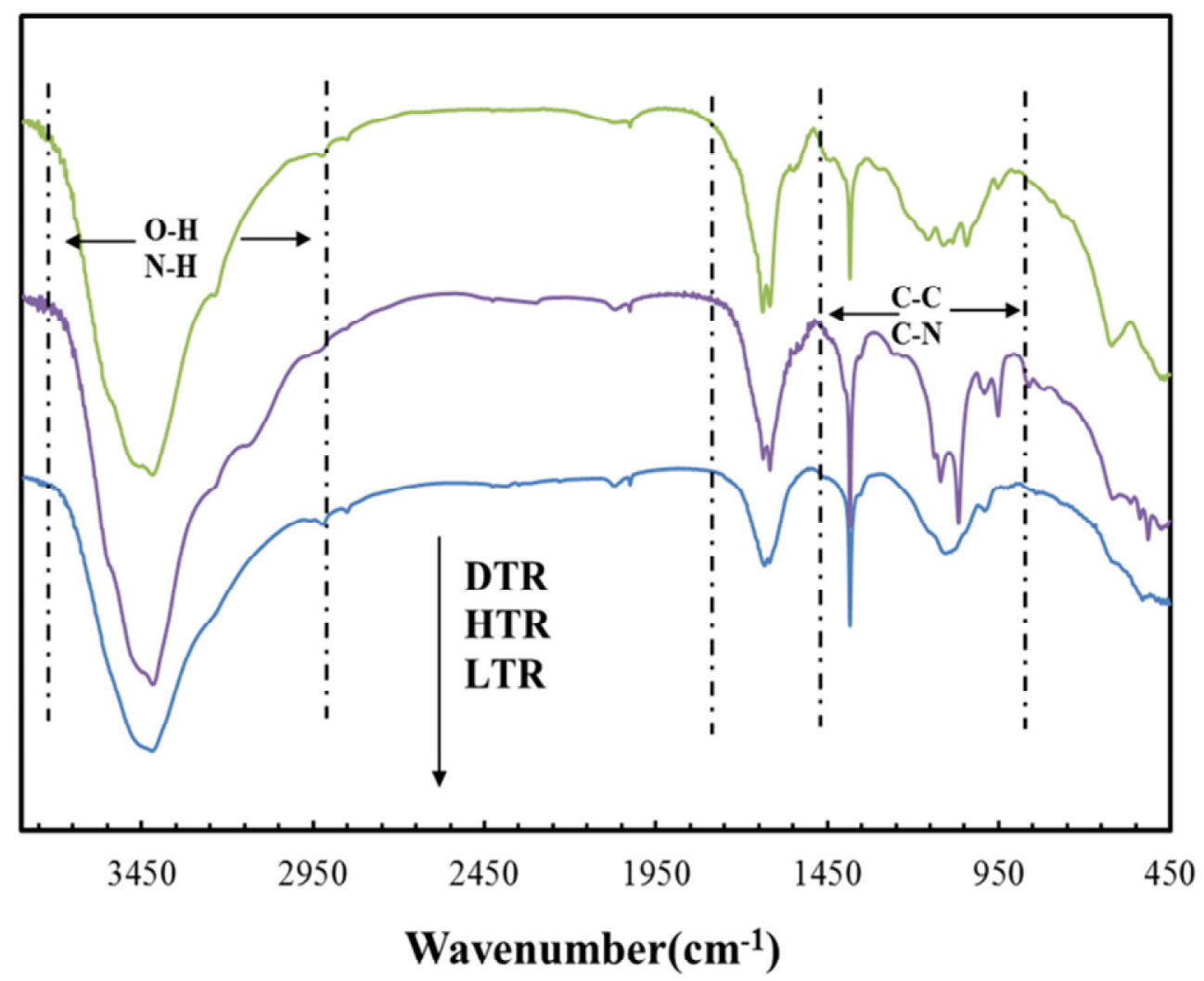

Fig 4. FTIR spectra of the prepared polymer catalysts

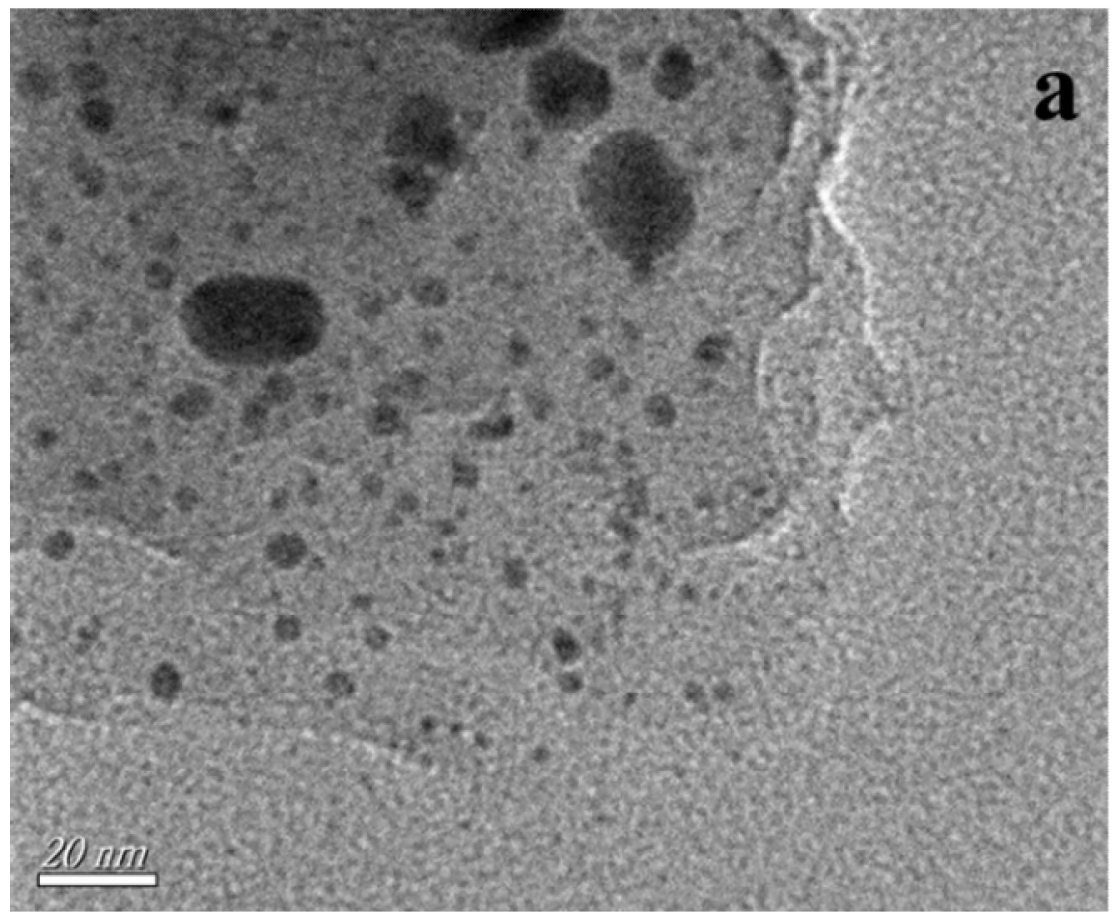



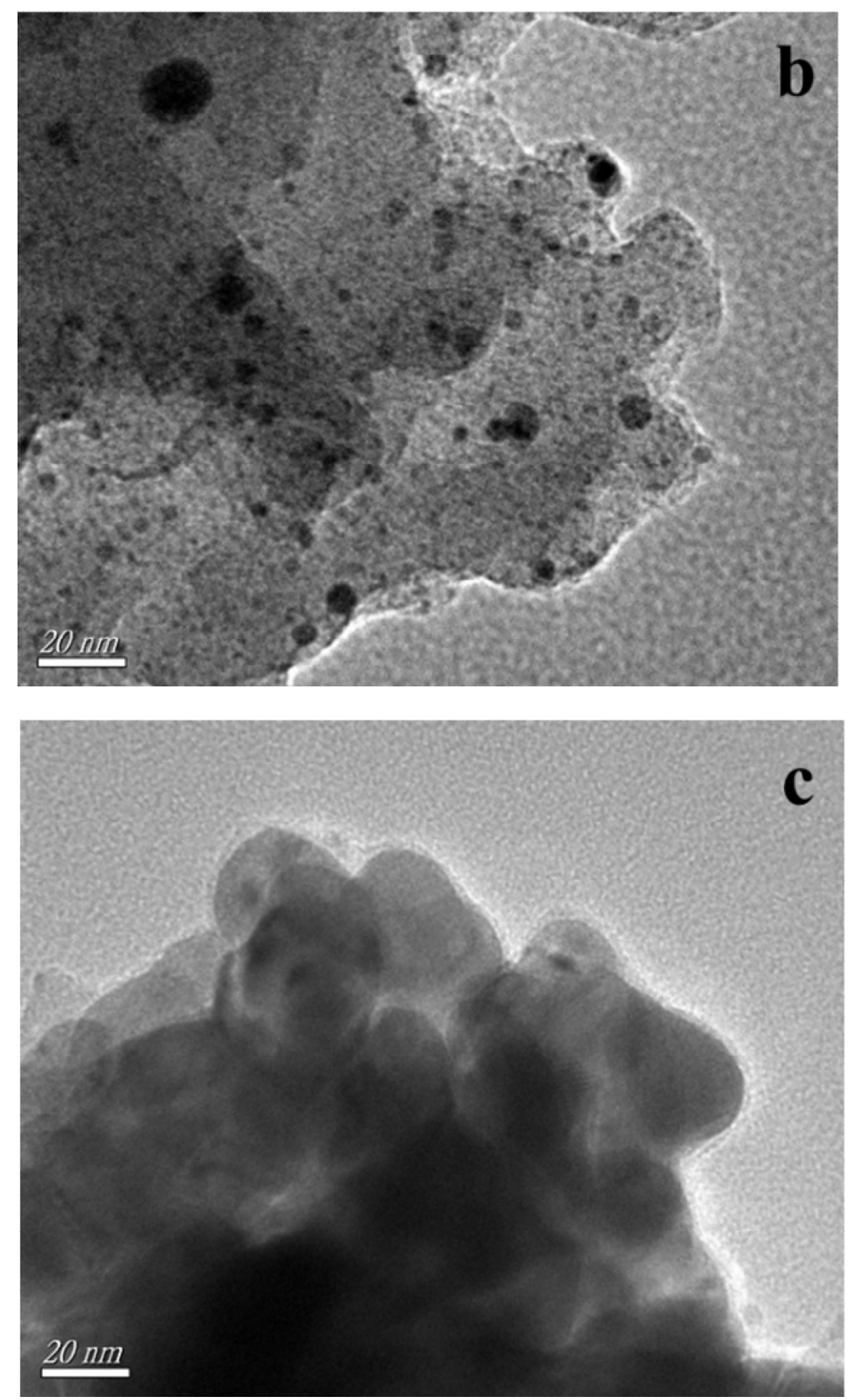

Fig 5. TEM images of the metal nanoparticles contained in the prepared polymer catalysts (a: DTR; b: HTR; c: LTR)

The presence of the encapsulated Ag nanoparticles in the prepared polymers has been further confirmed by the SPR spectra (Fig 6) where the Ag nanoparticles exhibit the typical SPR peaks at $\sim 415 \mathrm{~nm}$ [38-40]. There is no Ag in LTR, so there is no peak in $415 \mathrm{~nm}$. It is proved that the prepared polymer reactor is embedded with metal $\mathrm{Ag}$ nanoparticles. The silver nanoparticles in polymer catalytic reactors were also 
characterized by XRD. According to the test results (Figure 7), four characteristic peaks, $\{111\},\{200\},\{220\}$ and $\{311\},\{322\}$ appeared in the DTR. The standard spectral index shows that the four characteristic peaks are produced by the face-centered cubic silver particles [41], indicating that there are metallic silver particles in them. In contrast, there is the same face-centered cubic silver characteristic peak (HTR). However, in LTR, there was only a polymer peak, indicating that there was no silver in the sample. The results are consistent with the designed DTR and HTR containing silver particles, while the LTR contains no silver structure. It is proved that the structure of the three polymeric reactors is in accordance with the expected structure.

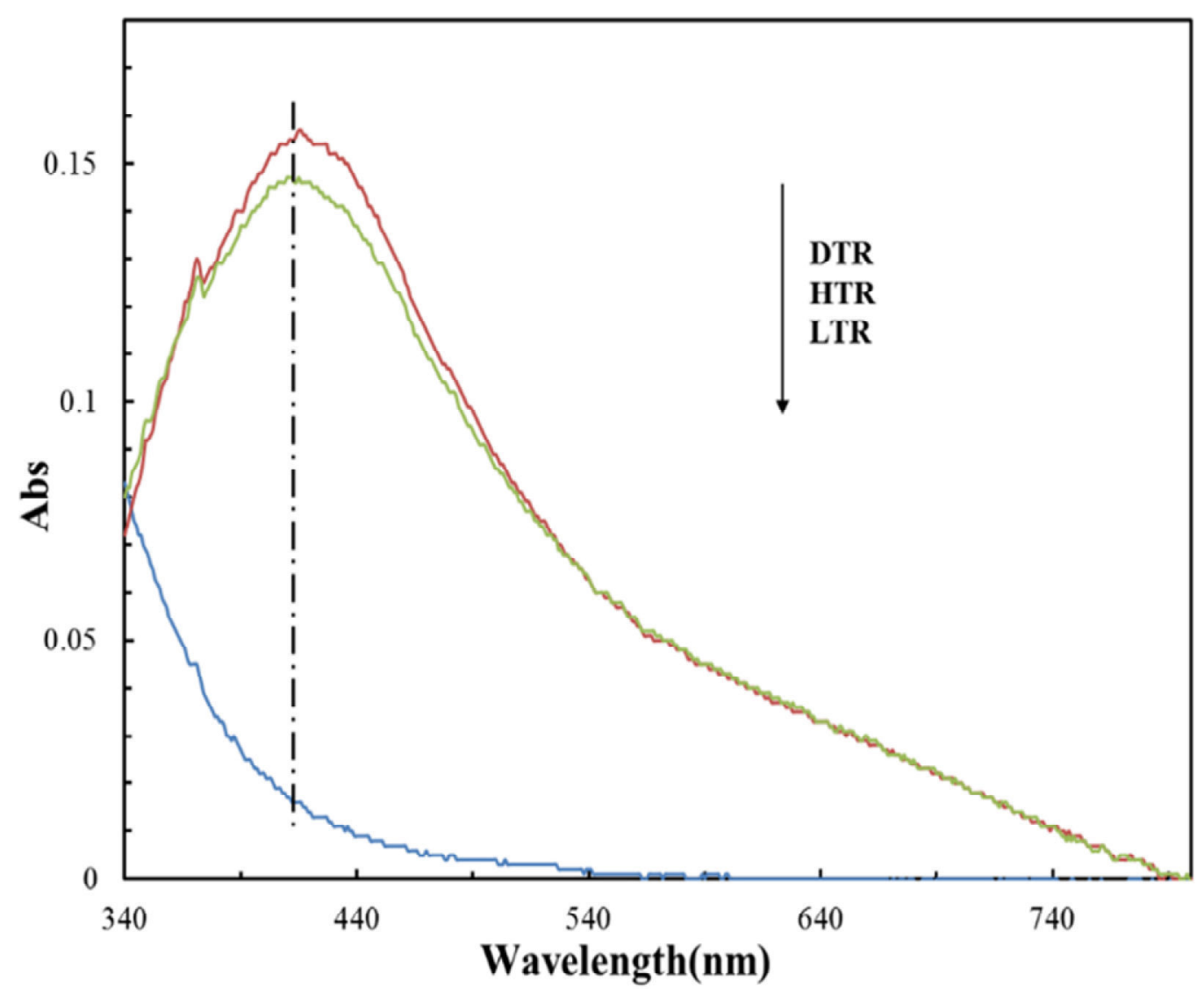

Fig 6. SPR spectra of the prepared polymer catalysts 


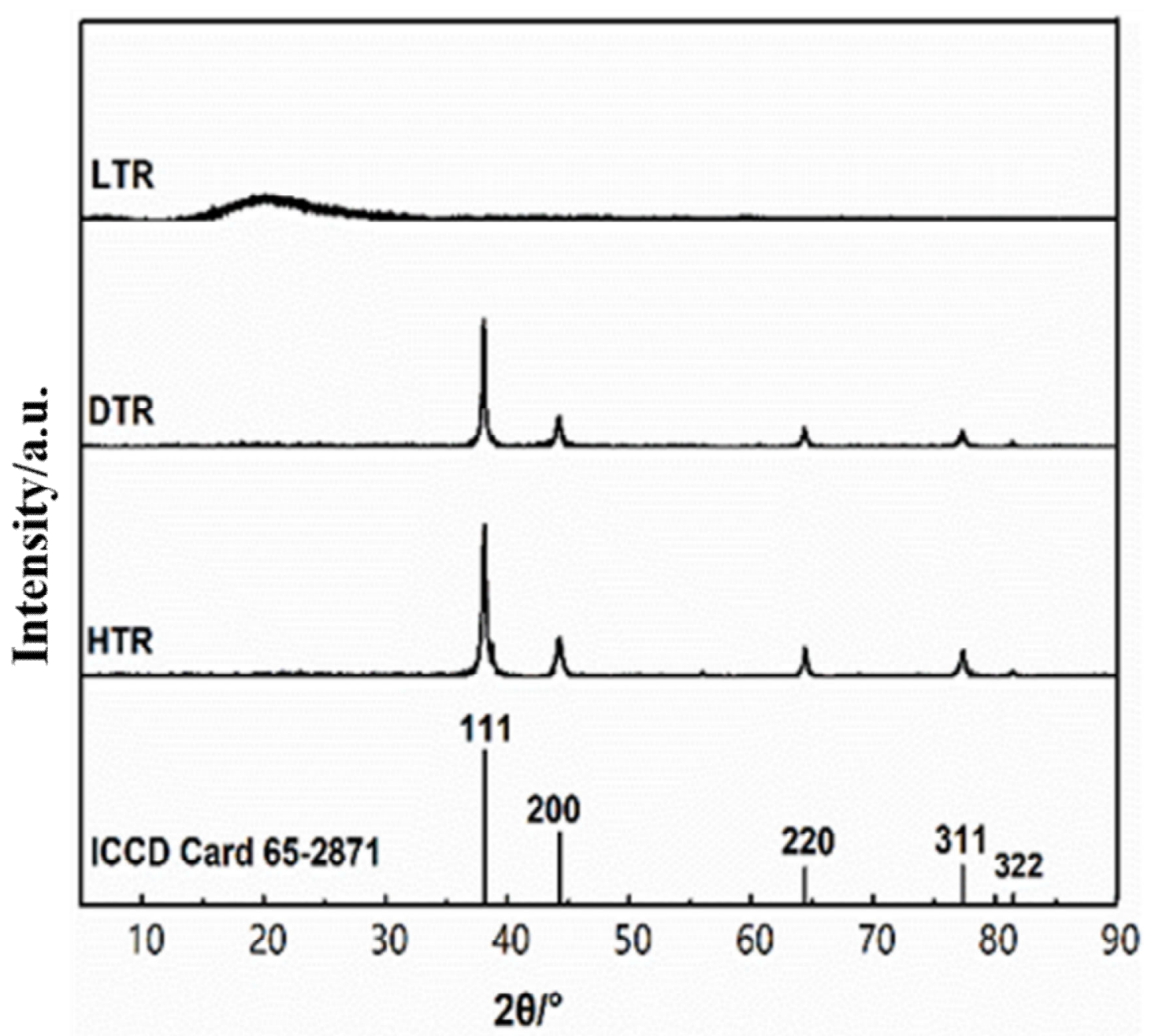

Fig 7. XRD spectra of the prepared polymer catalysts

The EDS data of DTR and HTR along with LTR are presented in Figure 8. It was found that common elements $\mathrm{C}, \mathrm{N}$, and $\mathrm{O}$ were contained in all three reactors. The synthesized DTR contains the elements of C, N, O, F, S, and Ag; HTR is composed of C, N, O, F, $\mathrm{Ag}$, and the elements contained in LTR are $\mathrm{C}, \mathrm{N}, \mathrm{O}, \mathrm{S}$, which are consistent with the different components described in sections 3.2. 


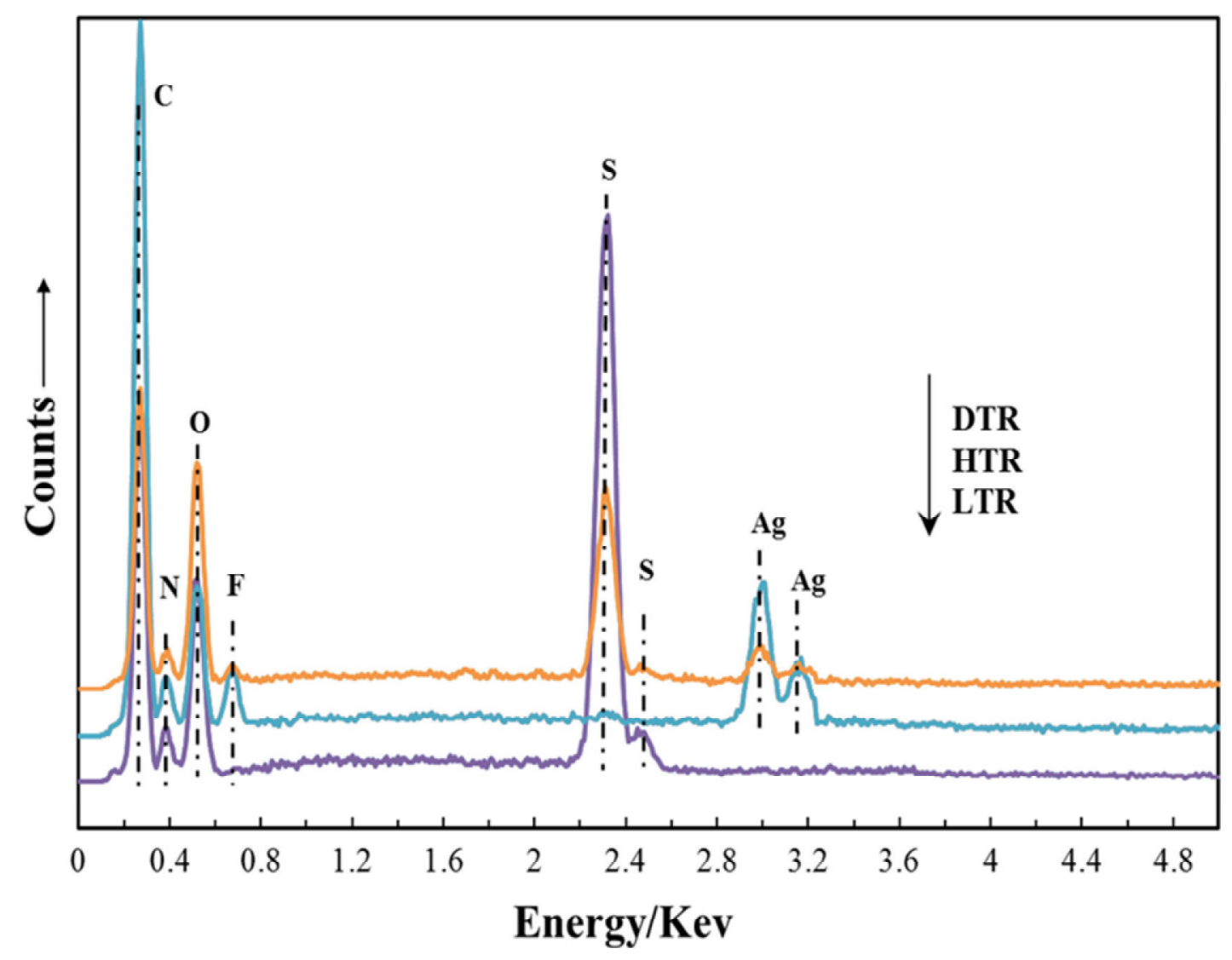

Fig 8. EDS spectra of the prepared polymer catalysts

\subsection{Evaluation of the self-switchable interactions}

To further address the thermosensitive ability of the bilayer structure, the PTFMA-PVI and PAM-PAMPS interactions were studied as a function of temperature, as shown in Figure 9a and Figure 9b. The dynamic radius of DTR increased with increasing temperature and the dramatic change appeared at ca. $37^{\circ} \mathrm{C}$ and $50^{\circ} \mathrm{C}$ (marked with broken lines), respectively. Below $37^{\circ} \mathrm{C}$, DTR showed relatively a smaller dynamic radius associating with the complementary interactions between PAM and PAMPS and between PVI and PTFMA (i.e., polymeric complexes), which inhibited swelling of the polymers. When the temperature was between $37^{\circ} \mathrm{C}$ and $50^{\circ} \mathrm{C}$, the dynamic radius of DTR dramatically increased in response to the dissociation of the self-healing interaction of PAM and PAMPS, which is nearly comparable to the dynamic radius change of LTR. Above $50^{\circ} \mathrm{C}$, the dynamic radius of DTR further increased significantly as the dissociation of the PVI and PTFMA, leading to completely open of the bilayer hydrogel polymer, which is similar to the changing trend to the dynamic radius change of LTR. In conjunction with the development of this polymer catalyst (cf. Scheme 1), 
this polymer reactor exhibited different admitting access to the active sites at a different temperature, thus enabling tandem/non-tandem switching ability at different temperature.
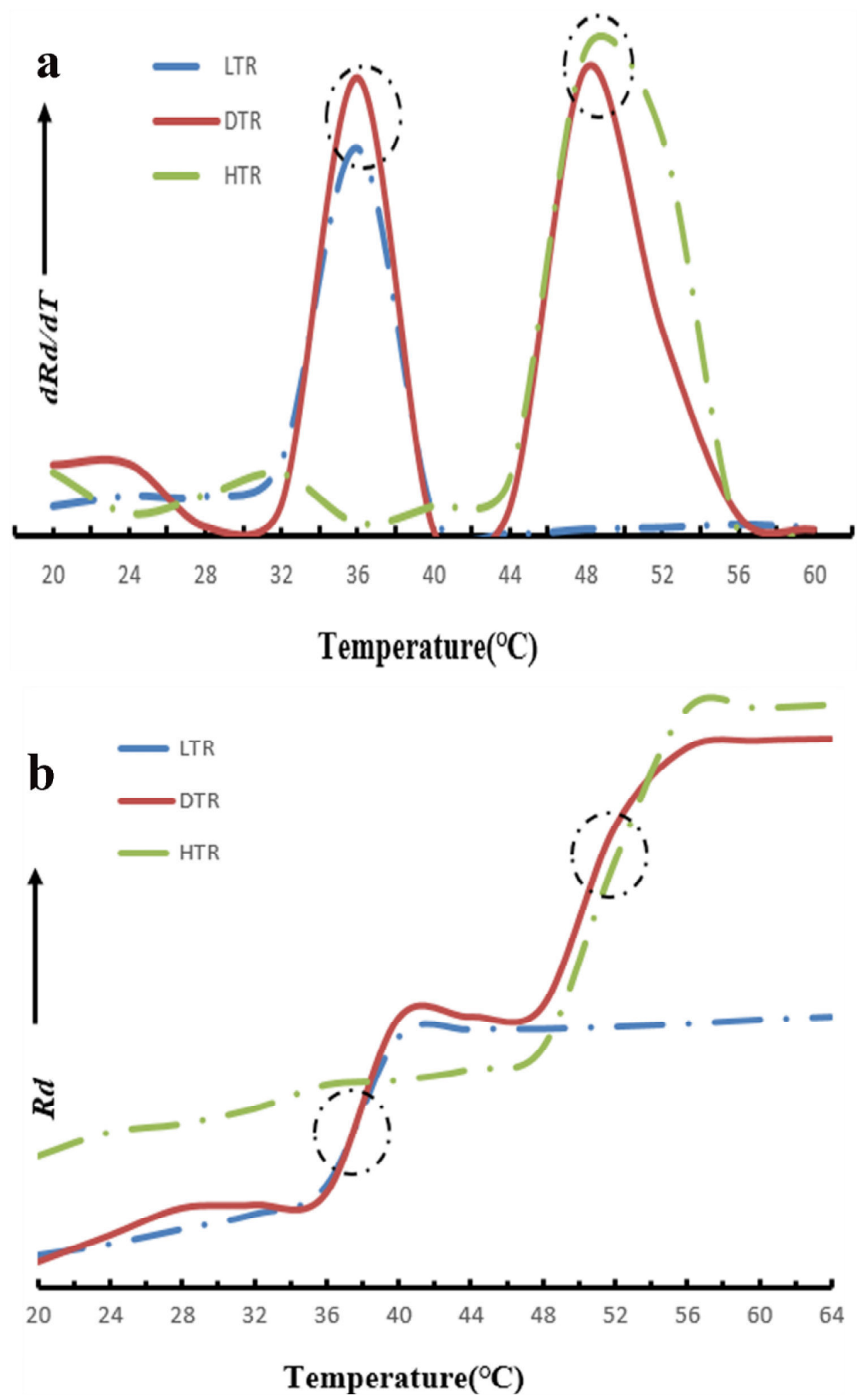

Figure 9. DLS spectra with dynamic-radius changing as a function temperature (a: Normal; b: Differential) 


\subsection{Change of shape in the switching process}

Figure 10 showed the shape change in the bilayer polymer reactor upon changing temperature. From section 3.3, we recognize that the two-layer polymer catalytic reactor has a phase transition temperature of $37{ }^{\circ} \mathrm{C}$ and $50{ }^{\circ} \mathrm{C}$. In order to facilitate the display of its macroscopic topography, we have recorded the topographical changes at three different temperatures of $30^{\circ} \mathrm{C}, 45^{\circ} \mathrm{C}$ and $60{ }^{\circ} \mathrm{C}$ using a digital camera (The three groups of temperatures are lower than the lowest phase transition $\left(37^{\circ} \mathrm{C}\right)$ temperature; higher than the lowest phase transition temperature $\left(37^{\circ} \mathrm{C}\right)$ and lower than the highest phase transition temperature $\left(50^{\circ} \mathrm{C}\right)$, and higher than the highest phase transition temperature $\left.\left(50^{\circ} \mathrm{C}\right)\right)$. The following electrochemical and catalytic tests were also tested at these three different temperatures. Fig 10a displays the slice of this catalyst appeared to be flat at $30^{\circ} \mathrm{C}$ but to be concave (Fig 10b) at the middle temperature $45^{\circ}$ and at $60^{\circ} \mathrm{C}$, it becomes flat again (Fig 10c). This result can be ascribed to the responsiveness of one layer in the middle temperature and responsiveness of both the two layers in the high temperature. The change in shape was reversible and this catalyst can be made to switch between a flat and a concave shape upon changing temperature.
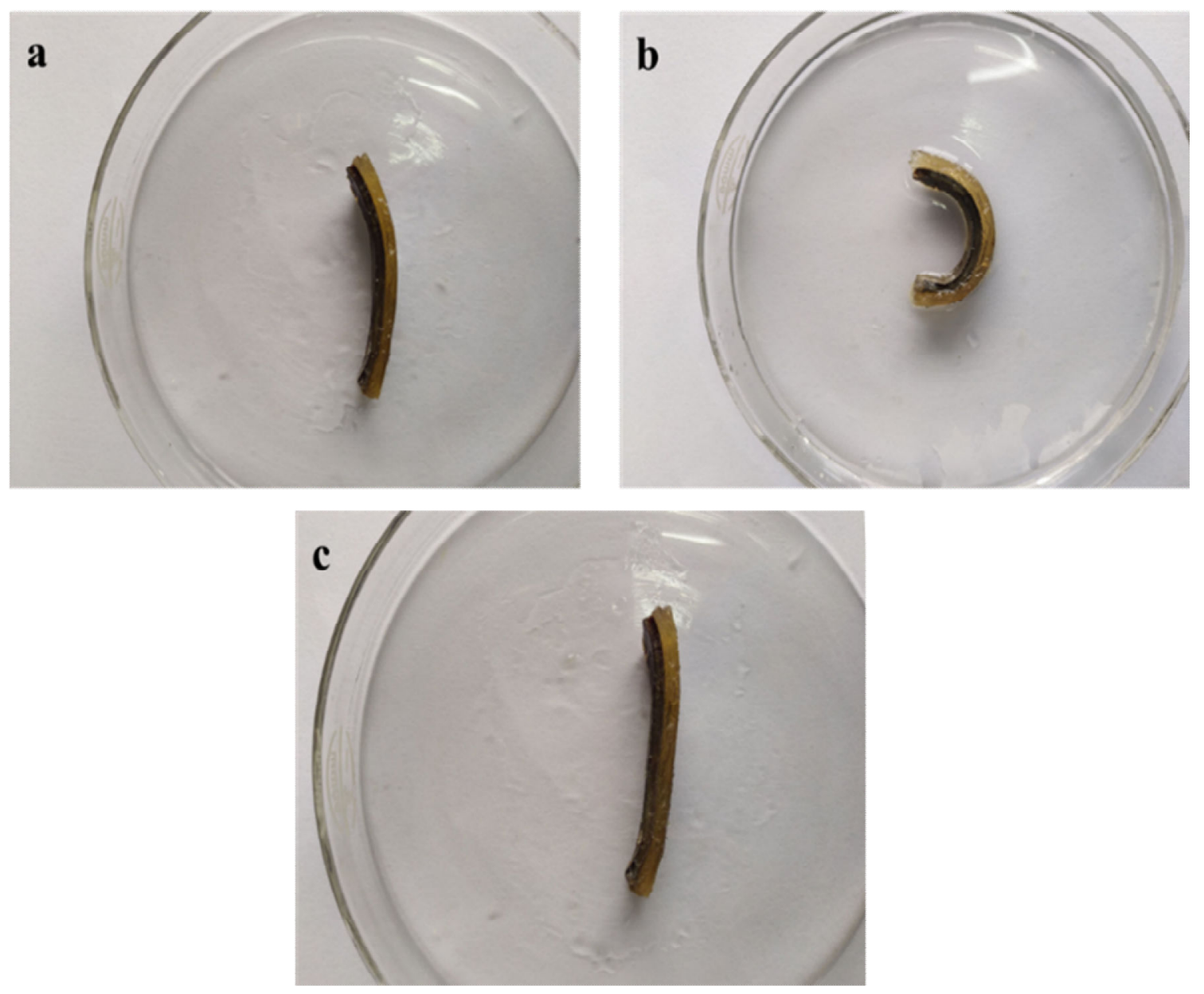
Figure 10. The shape change of DTR upon changing temperature: a $30^{\circ} \mathrm{C} ; \mathrm{b} 45^{\circ} \mathrm{C}$; c $60^{\circ} \mathrm{C}$.

\subsection{Self-controlled tandem catalysis}

The self-controlled catalytic properties of these polymer reactors were also evaluated by the hydrolysis and reduction process of NPA. UV spectroscopic analysis was used to monitor the catalytic reaction of NPA in the presence of sodium borohydride. As shown in Figure 11 , three representative temperatures $30^{\circ} \mathrm{C} 、 45^{\circ} \mathrm{C} 、 60^{\circ} \mathrm{C}$, were selected for a comparative study (illustrated in section 3.3). It can be clearly seen from Figure $11(\mathrm{a}, \mathrm{b}$, and $\mathrm{c})$ that there is no significant change in NPA $(271 \mathrm{~nm})$ at $30{ }^{\circ} \mathrm{C}$, mainly because of the channels of the catalysts LTR, DTR, and HTR are all closed, which makes NPA almost impossible to hydrolyze. Thus cascade reaction would not happen at this condition. At $45^{\circ} \mathrm{C}$, there is significant hydrolysis of NPA (Figure 11d) at the LTR catalyst, which can be attributed to the opening of the LTR channel and the exposure of acidic sites, while there is no obvious reduction reaction as the absence of the metal nanoparticles active sites. However, the HTR catalyst cannot cause significant changes in NPA (Figure 11e), mainly as the HTR channel switch is closed and the catalytic site is not exposed. At $45^{\circ} \mathrm{C}$, the catalytic effect of the catalyst DTR on NPA is almost similar to that of LTR. In Figure 11f, we can only see the hydrolysis of NPA to NP (400 nm), and the sequential reduction cannot occur as a result of the close tunnel of the reductive sites. The catalytic effect of LTR on NPA at $60{ }^{\circ} \mathrm{C}$ is not much different from that at $45{ }^{\circ} \mathrm{C}$ because of the absence of the reductive sites (Figure 11g). The catalytic reaction of NPA in the DTR system at $60{ }^{\circ} \mathrm{C}$ has been found to be complicated. At this time, as the switch of the active site of both bilayer catalytic sites is open, the hydrolysis peak of NPA decreases and the final product peak of 4-aminophenol (295 $\mathrm{nm}$ ) increases (Figure 11h). In this process, the intermediate NP formed in the DTR system can be further reduced to AP, completing the tandem catalysis. A small part of the series reaction can also take place in the HTR system at $60{ }^{\circ} \mathrm{C}$ (Figure 11i). The reason for this is that the imidazole group in the HTR can hydrolyze the NPA and then take place in the series reaction, but its catalytic effect is far less than that of DTR. 

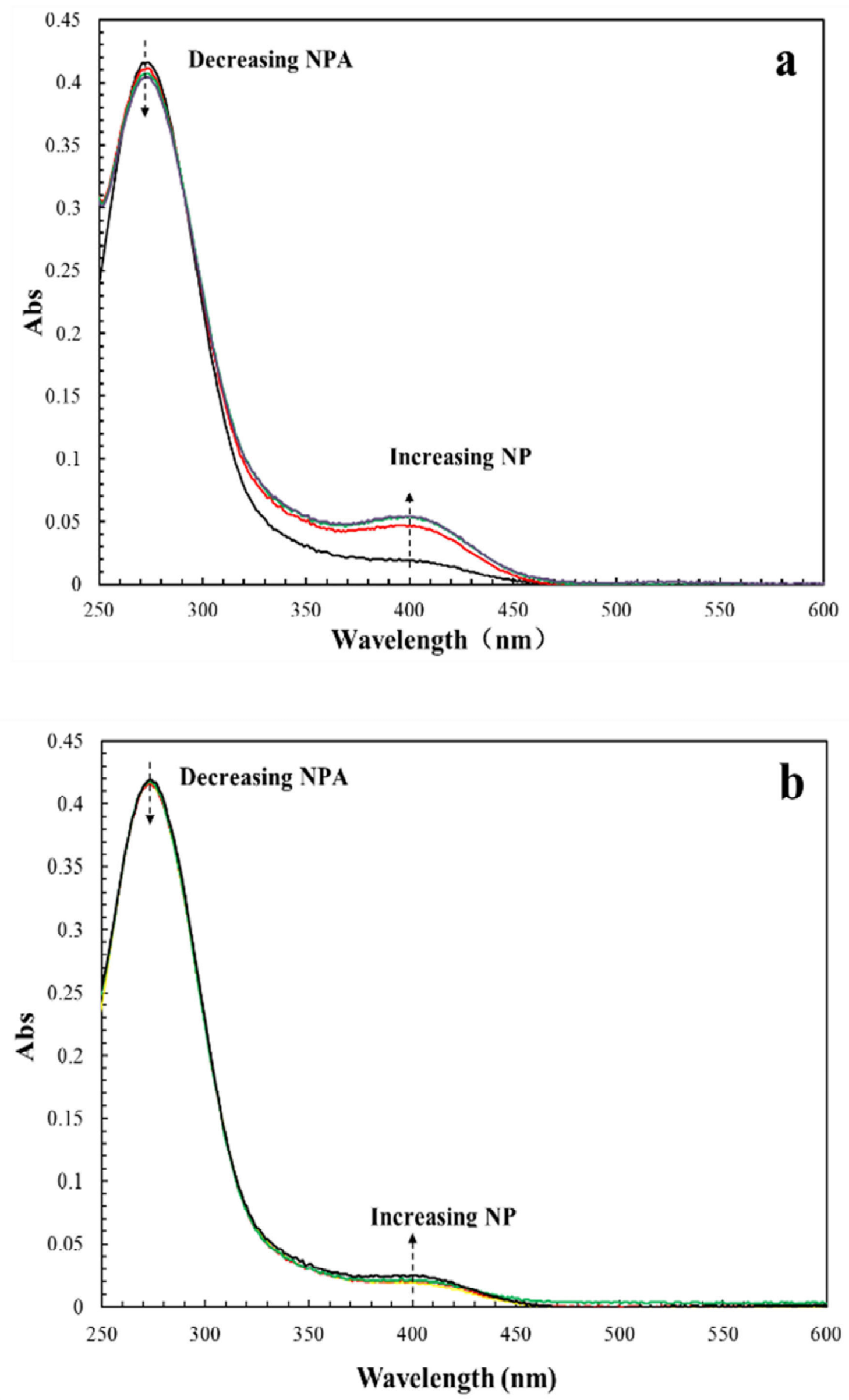

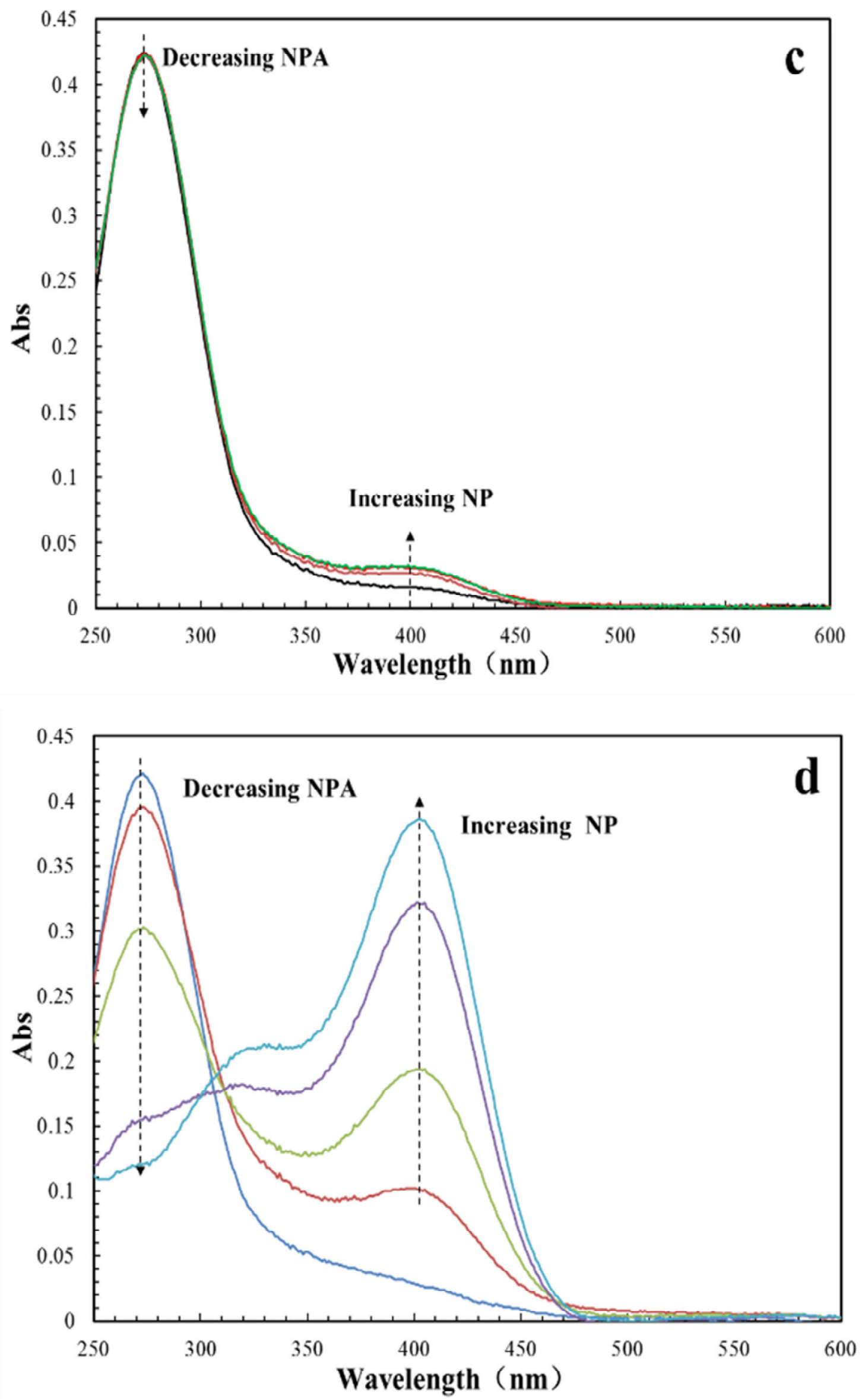

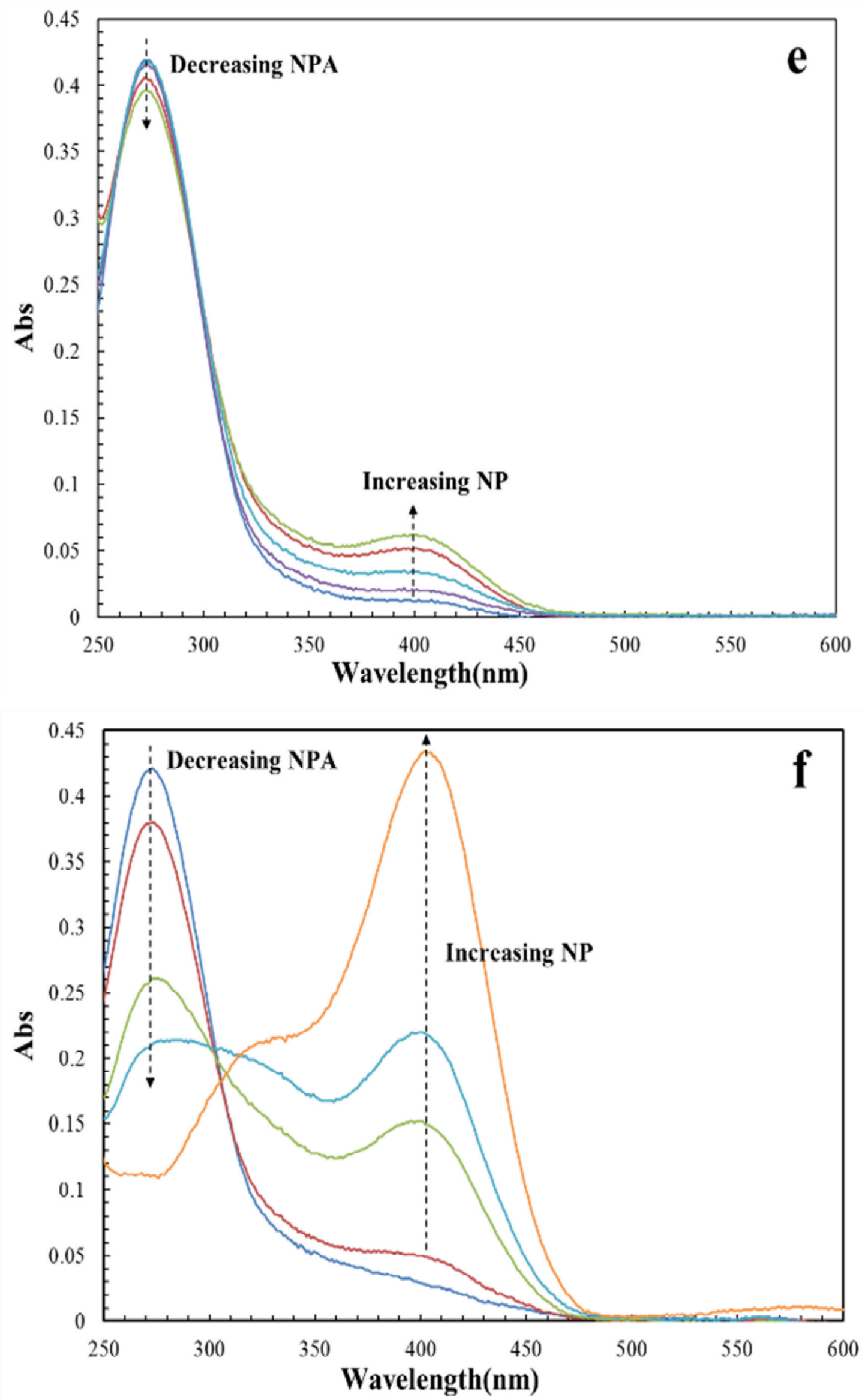

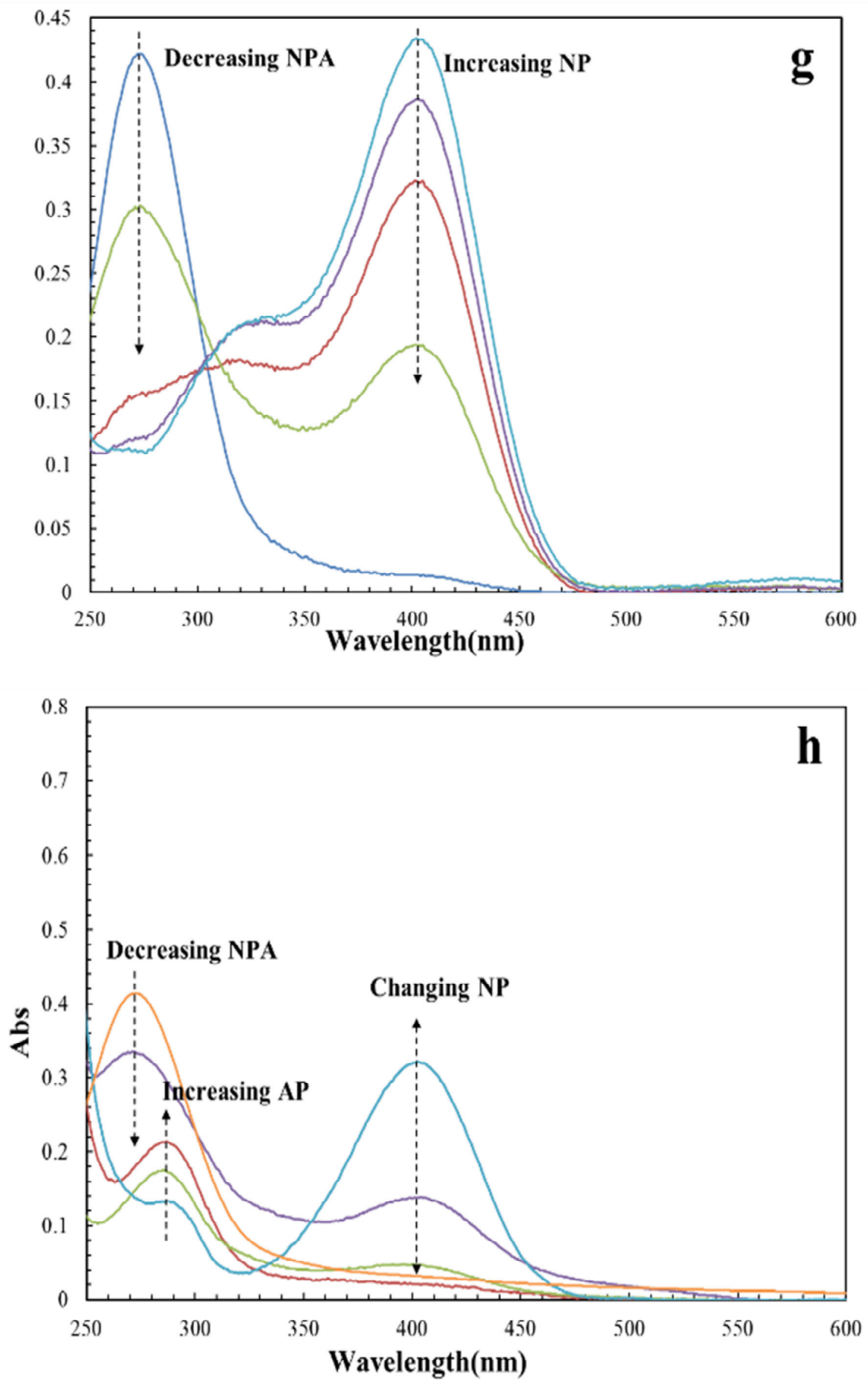


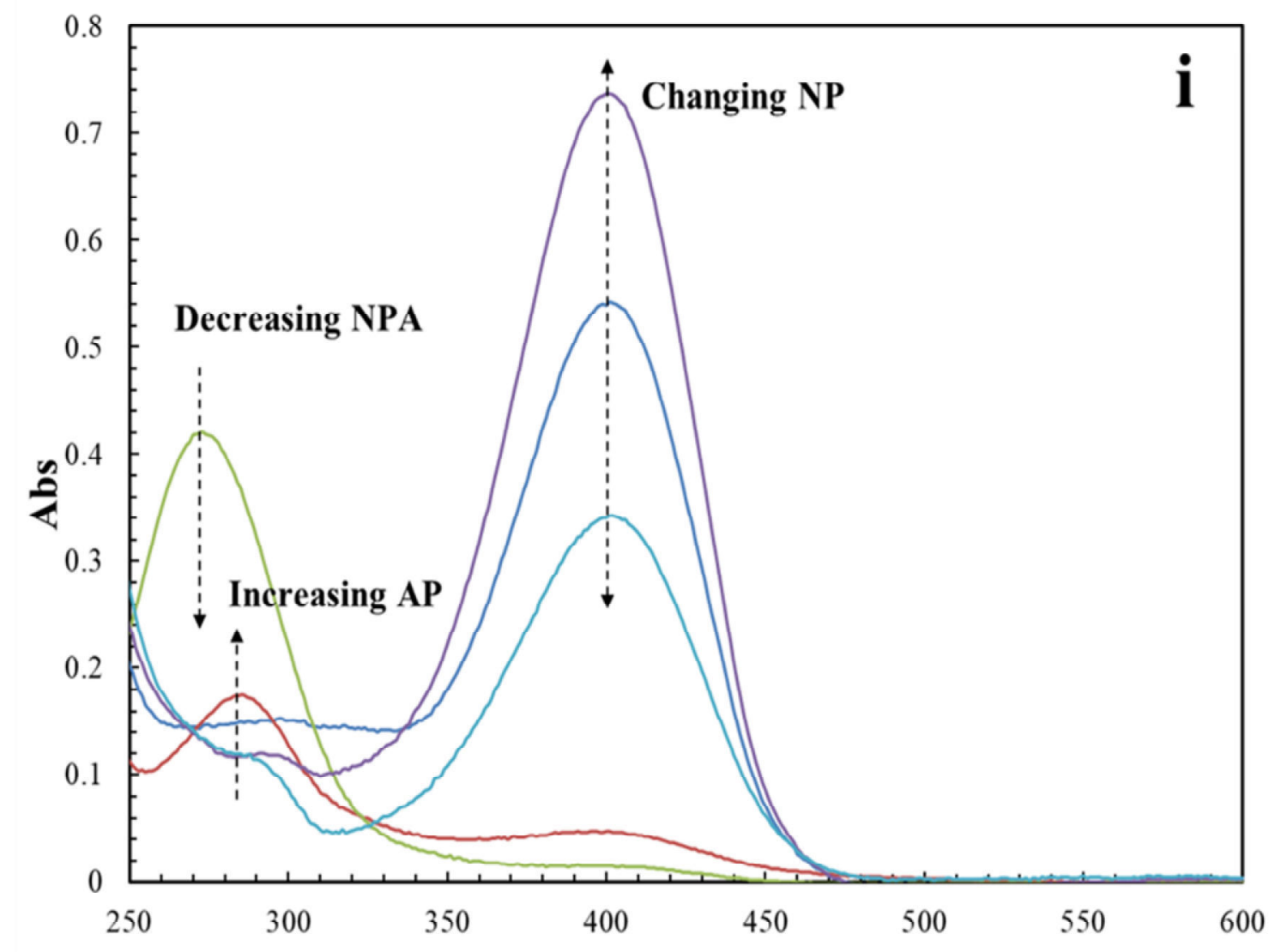

Figure 11. The changing UV spectrum of NPA in the presence of sodium borohydride at the prepared catalysts: a LTR at $30^{\circ} \mathrm{C}$; b HTR at $30{ }^{\circ} \mathrm{C}$; c DTR at $30^{\circ} \mathrm{C}$; d LTR at $45^{\circ} \mathrm{C}$; e HTR at $45^{\circ} \mathrm{C}$; f DTR at $45^{\circ} \mathrm{C}$; g LTR at $60{ }^{\circ} \mathrm{C}$; h HTR at $60{ }^{\circ} \mathrm{C}$; i DTR at $60{ }^{\circ} \mathrm{C}$.

\subsection{Dynamic-binding behaviour and switchable substrate channel}

As for the polymer reactors and the controllable mechanism, the basic issues focus on the interactions between the switchable moieties and the substrate [12]. Hence, it is of great significance to figure out the interactions between the different temperatureresponsive layers and the substrate. As a result, desorption electrochemistry has been conducted to gain information in the different switchable layers. It is known that the potential to reduce/oxidize a binding molecule depends upon the binding constant. Stronger binding needs relatively more energy to overcome the binding. The theory and details, as outlined in Scheme 3, have been widely described [13, 14, 42, and 43]. As schematically outlined in Scheme 3, the substrate molecules (B) in the system would generally involve desorption, diffusion to the surface of electrodes, and the terminal redox process. Therefore, the overall reaction rate in the system is determined by the 
slowest step (the rate-determining step). In the process, the diffusion has been eliminated with sonication. The overall reaction rate will be directly associated with the change of the redox reaction. As such, the desorbing electrochemistry was performed in accordance with the paradigm. Given the switchable properties of the novel catalyst, $30^{\circ} \mathrm{C} 、 45^{\circ} \mathrm{C}$ and $60^{\circ} \mathrm{C}$ were selected again for a comparative study (explained in 3.3 and 3.4). As shown in Figure 12, NPA which was attached to the first layer of DTR at $30^{\circ} \mathrm{C}$ exhibited adsorption/reduction peak at $-412 \mathrm{mV}$ (Fig 12a). In contrast, this peak at $45^{\circ} \mathrm{C}$ shifted to a smaller position $(-440 \mathrm{mV}$ ) (Fig 12b). There was no obvious shift appearing in this peak at $65^{\circ} \mathrm{C}$, in contrast to that at $45^{\circ} \mathrm{C}(-440 \mathrm{mV}$ vs $-442 \mathrm{mV}$; Fig. 12c). The results were similar for NP, where NP that was attached to the second layer of DTR at $30^{\circ} \mathrm{C}$ and $45^{\circ} \mathrm{C}$ exhibited comparable desorption/reduction potentials (-412 $\mathrm{mV}$ vs $-411 \mathrm{mV}$; Fig. $12 \mathrm{~d}$ and e). This peak at $65^{\circ} \mathrm{C}$ shifted to a higher position (i.e., $432 \mathrm{mV}$ ) (Fig 12f). DTR showed strong binding with NPA at relatively higher temperatures yet strong binding with NP at relatively higher temperatures. The switchable interactions between DTR and substrates clearly suggest the hierarchical access in the prepared DTR.

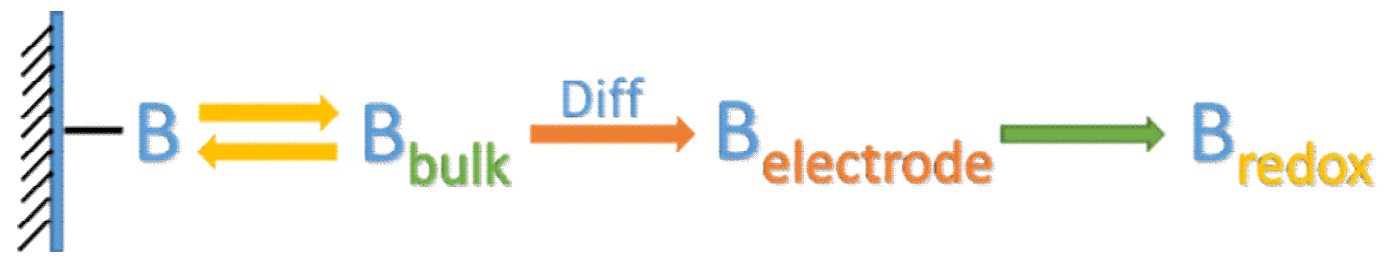

Scheme 3. Schematic presentation of the electrochemical process with the binding molecule B.

To further address this, Table 1 displayed the reduction potentials of both NPA and NP desorbing from all the prepared catalysts. The potentials at DTR exhibited an initial shift for NPA at $45{ }^{\circ} \mathrm{C}$ and then another shift for NP $65^{\circ} \mathrm{C}$. There was no significant change in the interaction between NPA and the second layer (HTR). NP and the first layer (LTR) have similar test results. The potential at LTR showed a maximal shift for NPA at $45^{\circ} \mathrm{C}$ in comparison to that at 30 and $60{ }^{\circ} \mathrm{C}$. The potential at HTR was however, subject to the main shift for NP at $65{ }^{\circ} \mathrm{C}$. In conjunction with the catalytic properties (cf. Fig 11), this result indicates again that the alterable tandem catalytic abilities lie in the DTR polymer reactor, which induced blocked substrate sequenced entrance to the acid catalytic sites and Ag nanoparticles and therefore made possible the sortable catalytic ability. 

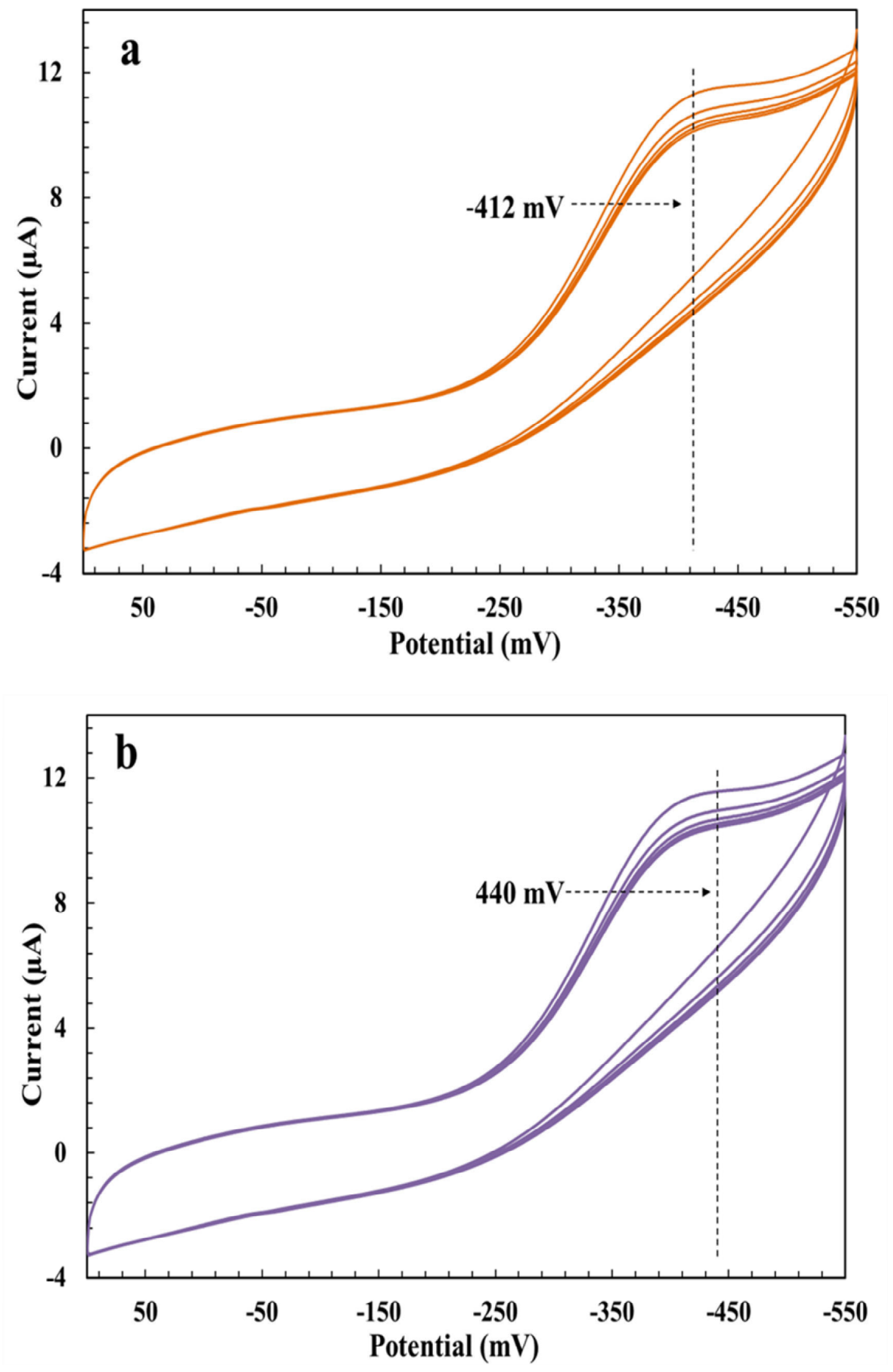

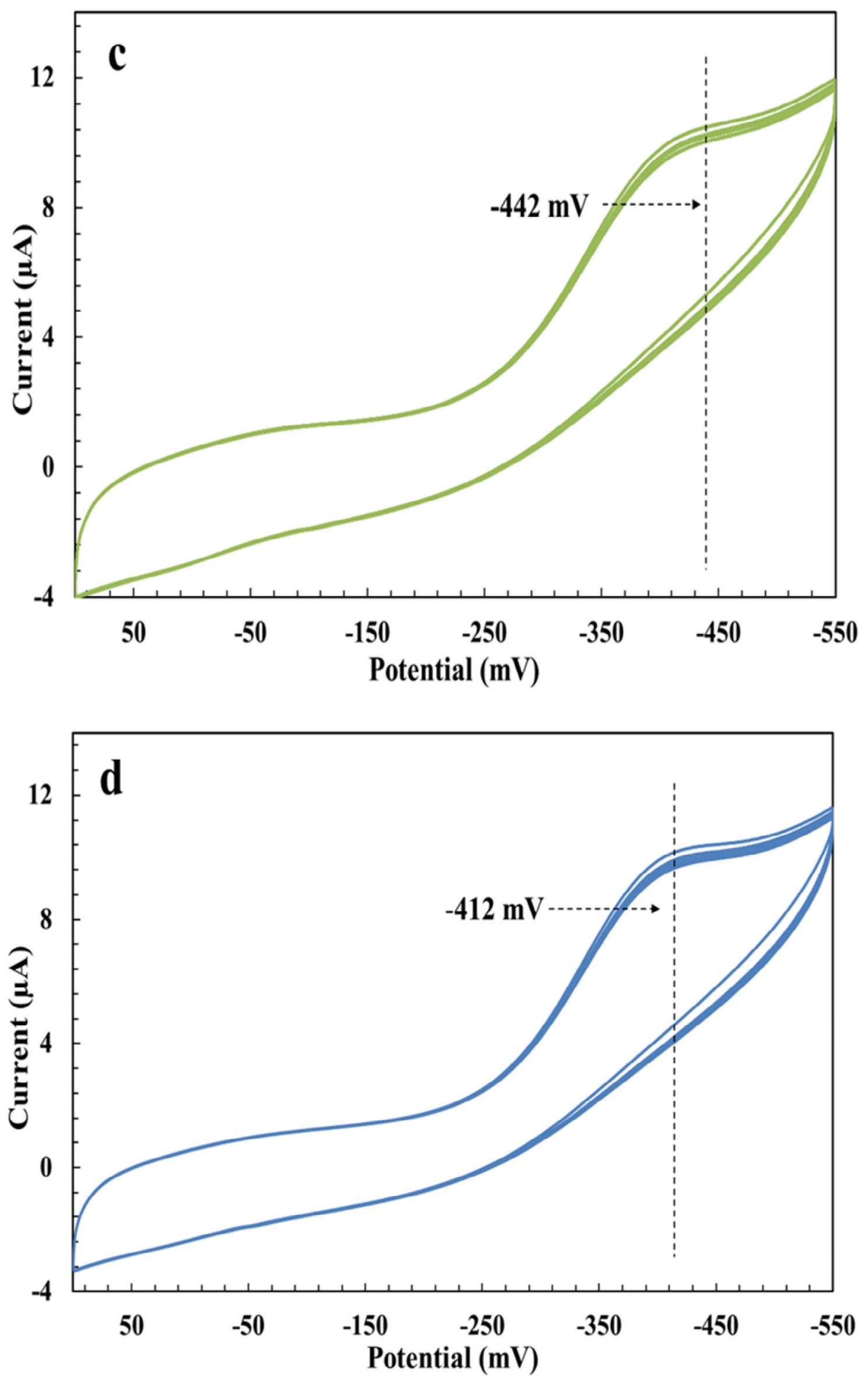

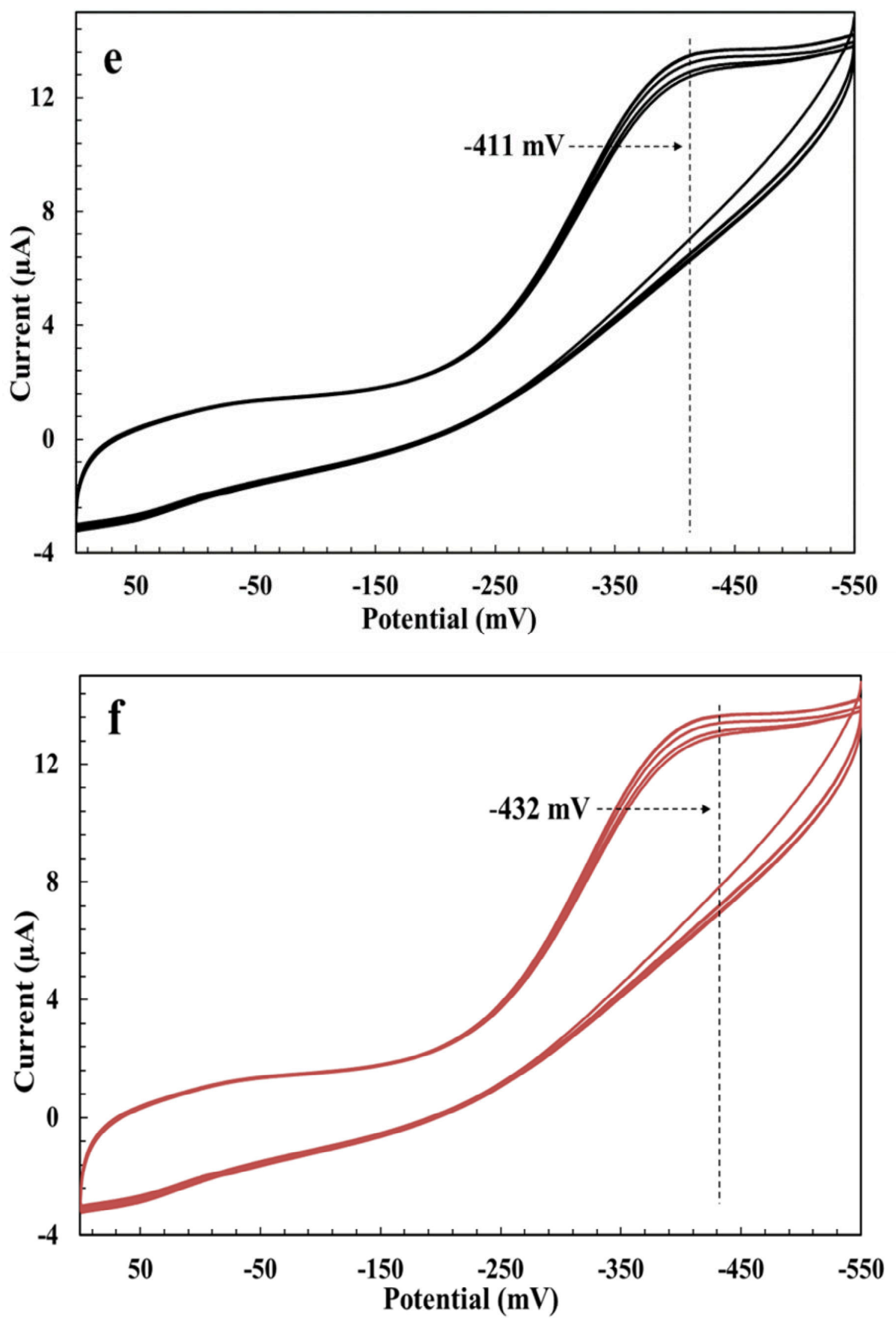

Figure 12. Reduction profiles with substrate desorbing from DTR (a: NPA at $30^{\circ} \mathrm{C}$; b: NPA at $45^{\circ} \mathrm{C}$; c: NPA at $65{ }^{\circ} \mathrm{C}$; d: NP at $30{ }^{\circ} \mathrm{C}$; e: NP at $45^{\circ} \mathrm{C}$; f: NP at $65^{\circ} \mathrm{C}$ ). 
Table 1. Reduction potentials $(\mathrm{mV})$ with substrates desorbing from all the prepared polymer catalysts

\begin{tabular}{ccccccc}
\hline \multirow{2}{*}{ Polymer catalyst } & \multicolumn{2}{c}{$30^{\circ} \mathbf{C}$} & \multicolumn{2}{c}{$\mathbf{4 5}^{\circ} \mathbf{C}$} & \multicolumn{2}{c}{$\mathbf{6 0}^{\circ} \mathbf{C}$} \\
\cline { 2 - 7 } & NPA & NP & NPA & NP & NPA & NP \\
\hline DTR & -412 & -412 & -440 & -411 & -442 & -432 \\
\hline LTR & -415 & -432 & -416 & -431 & -439 & -431 \\
\hline HTR & -398 & -405 & -405 & -406 & -415 & -430 \\
\hline
\end{tabular}

\section{Conclusions}

In the present study, we have reported a novel artificial polymer reactor with a selfcontrolled cascade/non-cascade ability. This "smart" catalyst was fabricated with two unique functional layers containing respectively acidic and metal catalytic sites, able to respond to different temperature ranges. The first layer has consisted of 2-acrylamido2-methylpropanesulfonic acid (AMPS) and acrylamide (AAM), which would responsive to moderate temperature because of the weak hydrogen bond between them. While the second layer is composed of 2-trifluoromethylacrylic acid (TFMA) and 1vinyl imidazole (VI) with silver nanoparticles encapsulated, showing the responsive ability to high temperature. Owing to the responsive ability towards the different temperatures of different layers, this reactor is capable of achieving cascade/noncascade reactions in different conditions. Therefore, it has been confirmed that polymer catalysts with self-controlled catalytic ability can be realized by this novel protocol. Future development in this field will significantly help increase the potential for further applications and create novel functional catalysts.

\section{Author Contributions:}

The manuscript was written through contributions of all authors. All authors have given approval to the final version of the manuscript.

\section{References}

[1] C. Crondal, M. Jeanty, D. Enders, Organocatalytic cascade reactions as a new tool in total synthesis, Nat. Chem. 2 (2010) 167-178.

[2] M. J. Climent, A. Corma, S. Iborra, M. Mifsud, MgO nanoparticle-based 
multifunctional catalysts in the cascade reaction allows the green synthesis of antiinflammatory agents, J. Catal. 247 (2007) 223-230.

[3] K. C. Nicolaou, J. S. Chen, The art of total synthesis through cascade reactions, Chem. Soc. Rev. 38 (2009), 2993-3009.

[4] E. Raluy, I. Favier, A. M. Vinasco, C. Pradel, E. Martin, D. Madec, E. Teuma, M. Gómez, A smart palladium catalyst in ionic liquid for tandem processes, Phys. Chem. Chem. Phys. 13 (2011), 13579-13584.

[5] P. Tanner, O. Onaca, V. Balasubramanian, W. Meier, C. G. Palivan, Enzymatic cascade reactions inside polymeric nanocontainers: A means to combat oxidative stress, Chem. Eur. J. 17 (2011), 4552-4560.

[6] P. V. Dau, S. M. Cohen, A bifunctional, site-isolate metal-organic frameworkbased tandem catalyst, Inorg. Chem. 54 (2015), 3134-3138.

[7] Y. Yamada, C. K. Tsung, W. Huang, Z. Huo, S. E. Habas, T. Soejima, C. E. Aliaga, G. A. Somorjai, P. Yang, Nanocrystal bilayer for tandem catalysis, Nat. Chem. 3 (2011), 372-376.

[8] T. Terashima, A. Nomura, M. Ito, M. Ouchi, M. Sawamoto, Star-polymercatalyzed living radical polymerization: Microgel-core reaction vessel by tandem catalyst interchange, Angew. Chem. Int. Ed. 50 (2011), 7892-7895.

[9] H. Ge, B. Zhang, X. Gu, H. Liang, H. Yang, Z. Gao, J. Wang, Y. Qin, A tandem catalyst with multiple metal oxide interfaces produced by atomic layer deposition, Angew. Chem. Int. Ed, 55 (2016), 7081-7085.

[10] H. Peng, L. Xu, L. Zhang, K. Zhang, Y. Liu, H. Wu, P. Wu, Synthesis of coreshell structured TS-1@mesocarbon materials and their applications as a tandem catalyst, J. Mater. Chem. 22 (2012), 14219-14227.

[11] Y. Han, X. Yuan, M. Zhu, S. Li, M. J. Whitcombe, S. A. Pilesky, A catalytic and shape-memory polymer reactor, Adv. Funct. Mater. 24 (2014), 4996-5001.

[12] B. Peng, X. Yuan, M. Zhu, S. Li, An “active" and self-switchable nanoreactor, Polym. Chem. 5 (2014), 562-566

[13] X. Zheng, R. Luo, M. Zhu, S. Li, Polymer nanoreactor with "mobilityrecalling" domains for on/off switchable catalysis, ChemCatChem 7 (2015), 814-818.

[14] J. Yang, D. Shen, L. Zhou, W. Li, X. Li, C. Yao, R. Wang, A. M. Toni, F. Zhang, D. Zhao, Spatially confined fabrication of core-shell gold nanocages@ mesoporous silica for near-infrared controlled photothermal drug release, Chem. Mater, 25 (2013), 3030-3037. 
[15] R. Luo, M. Zhu, X. Shen, S. Li, Polymer catalyst with self-assembled hierarchical access for sortable catalysis, J. Catal. 331 (2015), 49-56.

[16] Z. Xia, W. Wei, M. Zhu, S. Wu, X. Shen. S. Li, Artificial reactor containing polymeric bilayer architectures for the formation of self-controlled tandem catalyticability, EXPRESS Poly. Lett. 14 (2020), 12-25.

[17]Y. Lu, W. Wei, M. Zhu, S. Wu, X. Shen, S. Li, Polymer reactor with alterable substrate channeling for the formation of cascade/non-cascade-switchable catalytic ability, https://doi.org/10.1007/s10904-019-01349-z.

[18] W. Wei, M. Zhu, X. Shen, S. Wu, S. Li, Switchable polymer reactor composed of mussel-inspired polymer that contains Au nanoparticles, RSC Adv. 6 (2016), 4286942875.

[19] G. Li, G. Liu, E. T. Kang, K. G. Neoh, X. Yang, pH-responsive hollow polymeric microspheres and concentric hollow silica microspheres from silica-polymer core-shell microspheres, Langmuir, 24 (2008), 9050-9055.

[20] W. Wei, T. Zhou, S. Wu, X. Shen, M. Zhu, S. Li, An enzyme-like imprintedpolymer reactor with segregated quantum confinements for a tandem catalyst, RSC Adv. 8 (2018), 1610-1620.

[21]C. Zuo, W. Wei, Q. Zhou, S. Wu, S. Li, Artificial active nanoreactor with nature-inspired sequential catalytic ability, ChemistrySelect, 2 (2017), 6149-6153.

[22] P. Xiao, S. Wu, X. Shen, M. Zhu, S. Li, Smart tandem catalyst developed with sundew's predation strategy, capable of catching, decomposing and assimilating preys, ChemCatChem 10 (2018), 5231-5241.

[23] J. Lu, J. Dimroth, M. Weck, Compartmentalization of incompatible catalytic transformations for tandem catalysis. J. Am. Chem. Soc.137 (2015), 12984-12989.

[24] D. P. Debecker, Innovative sol-gel routes for the bottom-up preparation of heterogeneous catalysts. Chem. Rec. 18 (2018), 662-675.

[25] L. Ionov, M. Stamm, S. Diez, Reversible switching of microtubule motility using thermoresponsive polymer surfaces, Nano Lett, 6 (2006), 1982-1987.

[26] Z. Sun, F. Lv, L. Cao, L. Liu, Y. Zhang, Z. Lu, Multistimul-responsive, moldable supramolecular hydrogels cross-linked by ultrafast complexation of metal ions and biopolymers, Angw. Chem. Int. Ed. 54 (2015), 7944-7948.

[27] R. R. Costa, C. A. Custódio, F. J. Arias, J. C. R-Cabello, J. F. Mano, Layerby-layer assembly of chitosan and recombinant biopolymers into biomimetic coatings with multiple stimuli-responsive properties, small 7 (2011), 2640-2649. 
[28] S. Gao, G. Tang, D. Hua, R. Xiong, J. Han, S. Jiang, Q. Zhang, C. Huang, Stimuli-responsive bio-based polymeric systems and their applications, J. Mater. Chem. B. 7 (2019), 709-729.

[29] C. H. Alarcón, S. Pennadam, C. Alexander, Stimuli responsive polymers for biomedical applications, Chem. Soc. Rev. 34 (2005), 276-285.

[30] N. Nath, A. Chikoti, Creating "smart" surfaces using stimuli responsive polymers, Adv. Mater. 14 (2002), 1243-1247.

[31] J. F. Mano, Stimuli-responsive polymeric systems for biomedical applications, Adv. Eng. Mater. 10 (2008), 515-527.

[32] P. M. Mendes, Stimuli-responsive surfaces for bio-applications, Chem. Soc. Rev. 37 (2008), 2512-2529.

[33] M. Jaspers, M. Dennison, M. F. J. Mabesoone, F. C. Mackintosh, A. E. Rowan, P. H. J. Kouwer, Ultra-responsive soft matter from strain-stiffening hydrogels, Nat. Commun. 5808 (2014), 1-8.

[34] L. Zhai, Stimuli-responsive polymer films, Chem. Soc. Rev. 42 (2013), 71487160.

[35] Y. Zhou, M. Zhu, S. Li, Self-switchable catalysis by a nature-inspired polymer nanoreactor containing Pt nanoparticles, J. Mater. Chem. A. 2 (2014) 6834-6839.

[36] S. Li, Y. Ge, S. A. Piletsky, A. P. F. Turner, A zipper-like on/off-switchable molecularly imprinted polymer, Adv. Funct. Mater. 21 (2011), 3344-3349.

[37] H.S. Andersson, I.A. Nicholls, Spectroscopic evaluation of molecular imprinting polymerization systems, Bioorg. Chem. 25 (1997) 203-211.

[38] Y. Cao, J. He, J. Sun, Fabrication of oriented arrays of porous gold microsheaths using aligned silver nanowires as sacrificial template, Materials Letters, 63 (2009), 148-150.

[39] J. Yang, J. Y. Lee, H. P. Too, Core-shell Ag-Au nanoparticles from replacement reaction in organic medium, J. Phys. Chem. B. 109 (2005), 19208-19212.

[40] Y. Lu, Y. Mei, M. Ballauff, M. Drechsler, Thermosensitive core-shell particles as carrier systems for metallic nanoparticles, J. Phys. Chem. B. 110 (2006), 3930-3937.

[41] Z. Zhu, Z. Lu, D. Wang, X. Tang, Y. Yan, W. Shi, Y. Wang, N. Gao, X. Yao, $\mathrm{H}$. Dong, Construction of high-dispersed $\mathrm{Ag} / \mathrm{Fe}_{3} \mathrm{O}_{4} / \mathrm{g}-\mathrm{C}_{3} \mathrm{~N}_{4}$ photocatalyst by selective photo-deposition and improved photocatalytic activity, Applied Catalysis B: Environmental 182 (2016) 115-122. 
[42] S. Li, Y. Ge, A. Tiwari, S. Cao, A temperature-responsive nanoreactor, Small 6 (2010) 2453-2459.

[43] R. Luo, M. Zhu, X. Shen, S. Li. Polymer catalyst with self-assembled hierarchical access for sortable catalysis, RSC Adv. 5 (2015), 5598-5603. 
2020-05-06

\title{
Smart bilayer polymer reactor with
} cascade/non-cascade switching catalyst characteri

\author{
Wei, W.
}

Elsevier

Wei W, Xiao P, Thakur VK, et al., (2020) Smart bilayer polymer reactor with cascade/non-cascade switching catalyst characteristics. Materials Today Chemistry, Volume 17, September 2020, Article number 100279

https://doi.org/10.1016/j.mtchem.2020.100279

Downloaded from Cranfield Library Services E-Repository 